\title{
Uncovering The Mechanism of Homogeneous Methyl Methacrylate Formation with P,N Chelating Ligands and Palladium: Favored Re- action Channels and Selectivities
}

\author{
Luke Crawford, David J. Cole-Hamilton, and Michael Bühl* \\ University of St. Andrews, School of Chemistry, North Haugh, St. Andrews, Fife, KY16 9ST, Scotland, United Kingdom \\ Supporting Information Placeholder
}

In memory of Prof Dr Paul von Rague Schleyer

\begin{abstract}
The catalytic alkoxycarbonylation of alkynes via palladium and $\mathrm{P}, \mathrm{N}$ ligands, studied through a prototypical reaction involving propyne methoxycarbonylation yielding methyl methacrylate, has been explored at the B3PW91-D3/PCM level of density functional theory. Four different reaction routes have been probed in detail, spanning those involving one or two hemilabile $\mathrm{P}$, $\mathrm{N}$ ligands and either hydride or carbomethoxy mechanisms. The cycle that is both energetically most plausible and congruent with experimental data involves $\mathrm{Pd}(0)$ and two $\mathrm{P}, \mathrm{N}$ ligands acting co-catalytically in turn to shuffle protons via both protonation and deprotonation reactions. Other mechanisms proposed in the literature can be discounted because they would lead to insurmountable barriers or incorrect selectivities. For the preferred mechanism, the P,N ligand is found to be crucial in determining the strong regioselectivity and intrinsically controls the overall turnover of the catalytic cycle with moderate barriers $\left(\Delta \mathrm{G}^{\ddagger}\right.$ of 20.1 to 22.9 $\mathrm{kcal} / \mathrm{mol}$ ) predicted. Furthermore, the necessary acidic conditions are rationalized via a potential dicationic channel.
\end{abstract}

\section{INTRODUCTION}

Alkyne alkoxycarbonylation is a transformation with 100 $\%$ atom efficiency that forms acrylate esters ${ }^{1-8}$. Methoxycarbonylation of propyne yields methyl methacrylate (MMA) - a small molecule feedstock crucial in industry due to its polymer poly(methyl methacrylate), more commonly known as Perspex. This material has a wide range of uses which include important surgical roles ${ }^{9}$, cosmetics and coatings, and as a rigid transparent plastic for windows, especially in transport ${ }^{10}$. There is also a growing demand from use in LCD screens ${ }^{11}$. Functionalization of propyne yielding the branched product of methoxycarbonylation has received considerable attention ${ }^{2,3,5-}$ ${ }^{7}$ and such chemistry has been extended to higher alkynes such as ethynyl benzene ${ }^{12}$ and alkynols ${ }^{13}$. Transition metals are key to many industrial processes ${ }^{14-16}$ and in the example of MMA formation from propyne, palladium complexes with $\mathrm{P}, \mathrm{N}$ chelating ligands play a key role in this transformation (Scheme 1).

\section{Scheme 1: Conditions ${ }^{2}$ for the formation of MMA involving P,N ligands from propyne.}

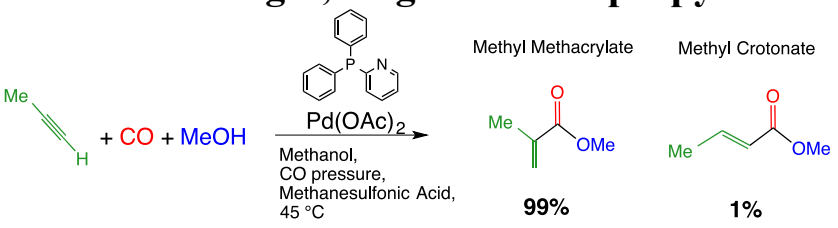

Drent has reported that the presence of a $\mathrm{P}, \mathrm{N}$ ligand, 2pyridyldiphenylphosphine $\left(2-\mathrm{PyPPh}_{2}\right)$, is necessary for both high selectivity for the branched product and a high turnover frequency (TOF) for carbonylation ${ }^{2,3}$. Ligands based upon 3$\mathrm{PyPPh}_{2}, 4-\mathrm{PyPPh}_{2}$ and $\mathrm{PPh}_{3}$ exhibit a reduced efficiency, suggesting that both the presence and location of the nitrogen atom is important. 2- $\mathrm{PyPPh}_{2}$ allows the methoxycarbonylation of propyne to proceed under mild conditions of $45{ }^{\circ} \mathrm{C}$, attaining a turnover frequency of 40,000 $\mathrm{mol}(\mathrm{mol} \mathrm{Pd} \mathrm{h})^{-1}$ with a selectivity of $\approx 99 \%$ towards MMA.

$\mathrm{P}, \mathrm{N}$ ligands are known to coordinate in a number of binding modes. While mono- and multiple unidentate coordination is typically through the softer phosphorus atom ${ }^{17}$, many structures have been isolated which show chelation ${ }^{18-24} \cdot 2-\mathrm{PyPPh}_{2}$ may also coordinate metal (hetero)dimers ${ }^{4,25-27}$ and structures involving iridium suggest that two 2- $\mathrm{PyPPh}_{2}$ ligands should be able to coordinate in both unidentate and chelating fashion around a single metal centre ${ }^{28}$.

Contrastingly, diphosphine ligands employed in the alkoxycarbonylation of other polymer precursors tend to remain bidentate in their coordination modes ${ }^{29-35}$. The hemilability of P,N-type ligands coupled with a wide range of coordination modes ${ }^{36}$ is one of the reasons for their continued use in catalysis $^{37-40}$, nanomaterials ${ }^{41}$ and as analytical molecular sensing agents ${ }^{42}$. This intrinsic property of $2-\mathrm{PyPPh}_{2}$ has been implicated in a number of proposed catalytic alkoxycarbonylation mechanisms.

The 2-PyPPh ${ }_{2}$ scaffold is the most effective for the methoxycarbonylation of propyne ${ }^{2}$. Through 6-methylation of the pyridyl moiety the selectivity towards MMA over the linear product, methyl crotonate (MC), was enhanced from $98.9 \%$ to $99.95 \%$ with a $20 \%$ increase in activity under some conditions ${ }^{3}$. More than two equivalents per Pd of a strong acid such as methanesulfonic acid (MeSA) are needed for efficient turn- 
over. Such an observation suggests an additional role of the acid beyond removing acetate and allowing coordination of ligands and substrates. Protonation of zero-valent Pd or the nitrogen of a hemilabile $2-\mathrm{PyPPh}_{2}{ }^{8}$ are therefore plausible candidates for forming the catalytically active species. Weak acids exhibit dramatically decreased TOFs and halide containing acids retard the reaction. Based on such evidence the active catalyst is probably a cationic Pd complex that is deactivated upon coordination of halides.

The simplest routes for catalytic turnover of MMA involve hydride and carbomethoxy pathways (Scheme 2). In the carbomethoxy route propyne inserts into the metal-carbonyl bond in a 1,2 mode with the bulky substituents at the $\beta$ position relative to $\mathrm{Pd}$ (cycle $\mathbf{A}$ ). During the hydride cycle, propyne insertion into the Pd-H bond follows a 2,1 mode (cycle B). An increased steric bulk at the 6 position, as in 2-(6-Me) $\mathrm{PyPPh}_{2}$, should have reversed effects upon product selectivity in both cases, with the carbomethoxy cycle encouraging MMA formation and preference for MC being increased if a classical hydride mechanism is operating.

\section{Scheme 2: Classical Pd-carbomethoxy (A) and Pd-hydride (B) mechanisms.}
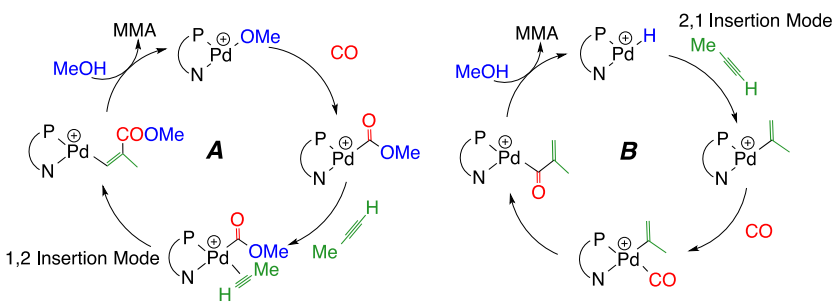

It has been argued that the role of $2-\mathrm{PyPPh}_{2}$ must extend beyond selectivity enhancement as the nature of the ligand is closely tied to the overall productivity of the catalytic cycle ${ }^{2}$ and therefore is likely acting as a rate-enhancing messenger for protonolysis in a carbomethoxy cycle, or as an in-situ base expediting the solvolysis of a "non-classical" hydride mechanism (Scheme 3).

\section{Scheme 3: Non-classical Pd-carbomethoxy (C) proposed by Drent and Scrivanti's non- classical Pd(0) mechanism (D) from labeling experiments.}
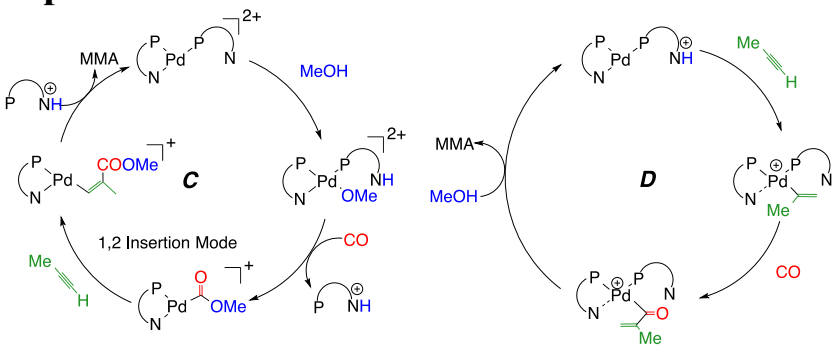

A non-classical hydride route operating in the formation of MMA was suggested due to the presence of a Pd vinyl intermediate, based on ethynylbenzene, being readily observed through ${ }^{1} \mathrm{H}$ NMR studies ${ }^{7}$. Should this route (D) be operating, the cycle would be initiated via proton transfer from $2-\mathrm{PyPPh}_{2}$ and subsequent steps would involve $\mathrm{CO}$ insertion and solvolysis with 2-PyPPh acting as an in-situ base. This non-classical hydride mechanism is proposed to occur via a $\operatorname{Pd}(0)$ complex. These are known to exist in mixtures of tertiary phosphines and protic solvents ${ }^{43-45}$, similar to conditions employed in alkoxycarbonylation reactions.

Dervisi et al. countered with evidence that would appear to support a non-classical carbomethoxy mechanism (cycle C) ${ }^{5}$ involving a dicationic complex and terminating protonolysis supported by $\mathrm{P}, \mathrm{N}-\mathrm{H}^{+} ; \mathrm{Pd}\left(2-\mathrm{PyPPh}_{2}\right)_{2}\left(\mathrm{CO}_{2} \mathrm{CH}_{3}\right)$ was found to be active towards branched small molecule production under $\mathrm{CO}$ pressure in methanol with propyne.

These experiments were conducted in the absence of acid with benzene as solvent, markedly different from turnover conditions, and do not inherently support a messenger protonolysis as in $\mathbf{C}$ nor discount either $\mathbf{C}$ or $\mathbf{D}$ operating in the presence of MeSA. Dervisi later confirmed ${ }^{6}$ the presence of the same vinyl intermediate suggested by Scrivanti but could not detect the $\sigma$-vinyl analogue expected with propyne, instead finding a phosphonium salt.

Recently Drent and Cole-Hamilton have provided a summary of the experimental evidence for the proposed reaction channels ${ }^{1}$. They argued that the bulkier groups of propyne being situated at the $\alpha$ carbon in the "non-classical" $\operatorname{Pd}(0)$ mechanism should evoke steric clashes. To overcome this a concerted protonation and nucleophilic attack of $\mathrm{Pd}^{0} \mathrm{CO}$ on coordinated propyne (Scheme 4) has been proposed. This would then be followed by a methanolysis step as in mechanism D. From this data, the exact nature of the catalytic cycle that accounts for the observed regioselectivities remains unknown. Support for a non-classical mechanism arises from reaction rates for a related transformation which are found to increase in line with $2-\mathrm{PyPPh}_{2}: \mathrm{Pd}$ ratio (until $30: 1$ ) and acid : Pd (until $66: 1)^{46}$ suggesting two coordinated P,N units with one of them likely protonated.

\section{Scheme 4: Alternative mechanism for the ini- tial carbonylation of propyne involving a con- certed nucleophilic attack and protonation ${ }^{1}$}

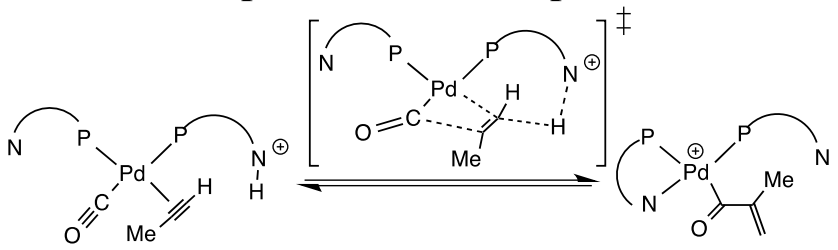

With these considerations we have tackled this problem using modern density functional methods. When experiment gives rise to ambiguous interpretation, quantum chemistry can offer insight that allows for a more definitive answer ${ }^{4-50}$, thereby aiding rational catalyst improvement. Our primary aims were in establishing an experimentally congruent route for alkyne alkoxycarbonylation, modeled through production of MMA. To this end, we characterized complete catalytic cycles for all four pathways, $\mathbf{A}-\mathbf{D}$, that had been proposed. Any plausible mechanism must have surmountable barriers compatible with the high turnover and must be able to closely reproduce the selectivities observed with both $2-\mathrm{PyPPh}_{2}$ and 2(6-Me) $\mathrm{PyPPh}_{2}$ ligands. Only one of the four proposed mechanisms, path $\mathbf{D}$, is able to achieve this. We have recently communicated the essential features of this mechanism ${ }^{51}$ and in the present paper we give a full account of the results that have led to its identification. 


\section{Scheme 5: Methoxycarbonylation at a Pd(II) center involving a 2-PyPPh $\mathbf{p}_{2}$ monochelate operating through cycle A. Profile sketched according to computed $\Delta$ G values (italics). TS4-5 determines regioselectivity and TS6-7 controls turnover.}

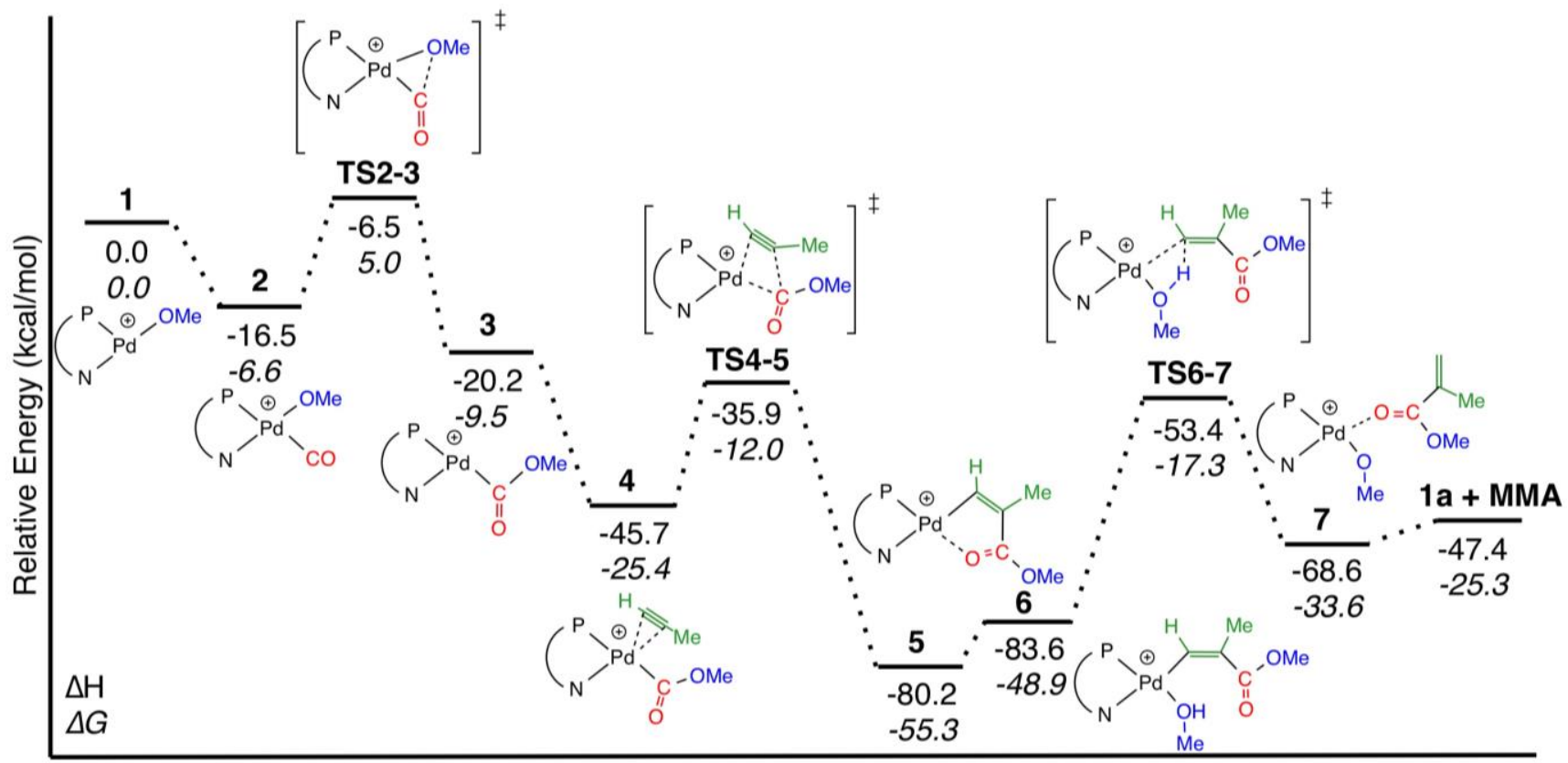

Reaction Coordinate

\section{COMPUTATIONAL METHODOLOGY}

We have used the B3PW91 ${ }^{52-54}$ hybrid functional which has been successfully validated for a range of reactions that rely upon metals ${ }^{55-58}$ and has been used to study related (2pyridyl)thiourea $\mathrm{Pd}(\mathrm{II})$ complexes $^{59}$. This method benchmarks well against explicitly correlated $\operatorname{CCSD}(\mathrm{T})^{60}$ when coupled with Grimme's DFT-D3 ${ }^{61-63}$, including Becke-Johnson damping $^{64,65}$. This post-calculation empirical correction serves to account for dispersive forces that are not well described by DFT yet have been shown to be essential for the reproduction of accurate energies, especially when triphenylphosphine and similarly bulky moieties are present ${ }^{66,67}$.

Geometries were computed at the level of B3PW91/ECP1 where ECP1 corresponds with the $6-31 \mathrm{G}^{* *}$ basis set on all non-metal atoms and the relativistic SDD pseudopotential and corresponding valence electron basis set on $\mathrm{Pd}$. Transition states were located at this level either through coordinate driving and subsequent optimization to the transition state or using the QST3 algorithm ${ }^{68}$. Stationary points were confirmed by the presence of the correct number of imaginary frequencies using the harmonic approximation. These frequencies allowed for corrections to enthalpies and free energies to be evaluated from standard thermodynamic expressions at 298.15 K. Transition states were confirmed to link to the respective reactants and products using intrinsic reaction coordinate (IRC) calculations ${ }^{69,70}$

Energies were refined through single point calculations employing the same functional and an ECP2 level i.e. the same SDD pseudopotential and valence electron basis set for Pd but the larger triple zeta $6-311+\mathrm{G}^{* *}$ basis set on all non-metal atoms. Bulk solvent effects were included through a polarizable continuum (PCM) $)^{71-74}$ with methanol as the solvent. We do not include the presence of the weakly coordinating anions arising from the protonation of $\mathrm{Pd}$-coordinated acetate. To these PCM and ECP2 corrected energies DFT-D3BJ corrections were added to accurately account for the missing disper$\operatorname{sion}^{75}$. All calculations were performed using Gaussian $09^{76}$ and structures were built by hand, guided by a small model study (see ESI, Scheme S1). A range of low energy conformers are known to exist for related rhodium species and preferential orientation is impacted little by the location of the pyridyl group ${ }^{77}$.

\section{RESULTS AND DISCUSSION}

We begin by exploring a carbomethoxy cycle (mechanism A in Scheme 2) as a potential route for the classical methoxycarbonylation of propyne to MMA involving one $\kappa^{2}-\left(2-\mathrm{PyPPh}_{2}\right)$ ligand at a Pd(II) center. Next, a classical hydride mechanism (B) is computed, followed by inspection of the "non-classical" routes $\mathbf{C}$ and $\mathbf{D}$ using a hemilabile $\kappa^{1}-\left(2-\mathrm{PyPPh}_{2}\right)$ as a proton relay (Scheme 3).

\section{1 - CLASSICAL CARBOMETHOXY (A)}

A classical methoxycarbonylation pathway begins with a single chelating 2- $\mathrm{PyPPh}_{2}$ ligand and requires the prior formation of a $\mathrm{Pd}(\mathrm{II})$ center with coordinated methoxide, such as $\left[\left(2-\mathrm{PyPPh}_{2}\right) \mathrm{Pd}(\mathrm{OMe})\right]^{+}(\mathbf{1}$, Scheme 5). Complex 1 would be unlikely to be present in significant amounts with excess acid under catalytic conditions; however we sought to exclude this route on the grounds of selectivity and the energetics of individual steps.

The first step of this cycle is the uptake of CO (2) and subsequent migratory insertion of the nucleophilic methoxy unit onto carbon monoxide affording $3^{78}$. This process is facile with a free energy barrier of $11.6 \mathrm{kcal} / \mathrm{mol}$ via TS2-3 and co- 
ordination of propyne affording 4 should be rapid. Propyne binds in a perpendicular orientation relative to the $\mathrm{Pd}-\mathrm{N}-\mathrm{P}$ plane (Figure 1) that shows no predisposition for regioselectivity at this stage. Subsequent MMA formation occurs via a 1,2 insertion through TS4-5, as opposed to MC formation which occurs via a 2,1 insertion (for the differences inherent in these processes see section 1.1). At this point in the reaction, coordinated propyne rotates from the perpendicular orientation in 4 towards an in-plane mode, decreasing the distance between bond forming carbon participants from $3.08 \AA$ to $2.02 \AA$. Concomitantly, the acyl moiety begins to dissociate from $\mathrm{Pd}$ and a stronger $\mathrm{Pd}-\mathrm{C}$ bond with propyne forms to compensate.

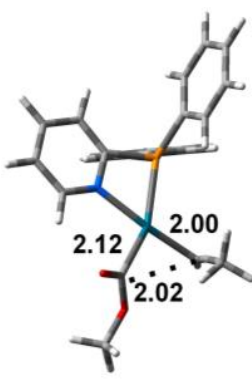

4
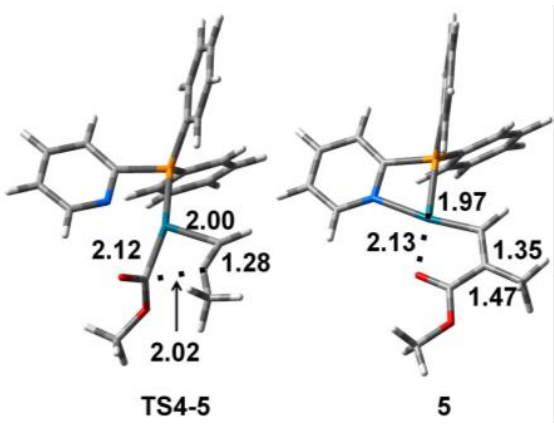

Figure 1: Geometries involved in Pd(II) mediated 1,2 insertion of COOMe and propyne. Distances in $\AA$. Blue $=\mathrm{N}$, Orange $=\mathrm{P}$, Turquoise $=\mathrm{Pd}$, Grey $=\mathrm{C}$, Red $=\mathrm{O}$ and White $=\mathrm{H}$.

The activation energy associated with forming the branched Pd-alkenyl intermediate, $\mathbf{5}$, is low at $13.4 \mathrm{kcal} / \mathrm{mol}$ relative to 4. Due to the considerable enthalpic and entropic gain upon insertion and the challenging kinetic barrier for terminating protonolysis, the palladium alkenyl ester $\mathbf{5}$ rests in a deep thermodynamic sink. From 5, TS6-7 has an imposing barrier of $38.0 \mathrm{kcal}$ for solvolysis - incompatible with turnover conditions. This step involves cleavage of a $\mathrm{Pd}-\mathrm{C}$ bond and the formation of a $\mathrm{C}-\mathrm{H}$ bond which is ultimately less favourable than retention of the $\mathrm{Pd}$ - alkenyl complex (7 vs. 5).

However the classic carbomethoxy mechanism is more complex than Scheme 5 suggests. After dissociation of the product, 1a has the methoxy group trans to phosphorus as opposed to trans to nitrogen of chelating 2- $\mathrm{PyPPh}_{2}$ as in $\mathbf{1}$. This leads to a continuation of the cycle to regenerate $\mathbf{1}$ through isomers 1a to 7a. Strictly, two MMA molecules are produced in every turn of this full catalytic engine and Scheme $\mathrm{S} 2$ in the ESI illustrates the energetic stipulations of producing MMA through this isomeric pathway.

The largest free-energy span along this second leg is protonolysis between 5a and TS6a-7a at $31.2 \mathrm{kcal} / \mathrm{mol}$, lower than the equivalent process in Scheme 5. Dynamic studies on $\mathrm{Pd}(\mathrm{II})$ 2-PyPPh $\mathrm{PH}_{2}$ systems have suggested that fluxional and ligand exchange processes are accessible without considerable barri$\mathrm{ers}^{36}$. If 1 and 1 a could interconvert rapidly, the two pathways presented may interweave to allow the system to traverse over the less imposing kinetic barriers and skirt the highest one. For instance, a path leading from $\mathbf{1 a}$ via $\mathbf{7 a}$ to $\mathbf{1}$ followed by isomerization of 1 to 1a would avoid the higher barrier via TS6-7.

The trigonal transition state between 1 and 1a has been located and found to be $17.5 \mathrm{kcal} / \mathrm{mol}$ relative to $\mathbf{1}$ while $\mathbf{1 a}$ is $11.0 \mathrm{kcal} / \mathrm{mol}$ above 1 . Due to the kinetic hindrance of this route as opposed to the rapid CO uptake by $\mathbf{1}$ it is unlikely that this process will form the major pathway. There are other points of such "pathway switching" however with $\mathbf{3}$ and $\mathbf{5}$ potential locales for isomerization through a trigonal transition state though irrespective of this a difficult barrier of at least 31 $\mathrm{kcal} / \mathrm{mol}$ must be crossed. Based on the energy profiles obtained, a classical carbomethoxy route is unlikely. To rule out this path conclusively, we now explore the MMA vs. MC selectivity of $\mathbf{4} \rightarrow \mathbf{5}$ and $\mathbf{4 a} \rightarrow \mathbf{5 a}$.

\section{1 - CLASSICAL CARBOMETHOXY SELECTIVITY}

The selectivity-determining step is the insertion of the perpendicular coordinated alkyne into the $\mathrm{Pd}-\mathrm{C}_{\text {(carbonyl) }}$ bond via TS4-5. Besides this 1,2-insertion step leading to the branched product, an alternative linear forming route through a 2,1 insertion (TS4L-5L) is possible (Scheme 6). Due to the lack of steric bulk surrounding a single chelating $2-\mathrm{PyPPh}_{2}$ ligand there is little discrimination between $\mathbf{4}$ and $\mathbf{4 L}$ though a distinct kinetic difference is observed between TS4-5 and TS4L5L.

\section{Scheme 6: Selectivity determining pathways for MC (left) and MMA (right) formation in the first Pd(II) carbomethoxy pathway. Ener- gies are taken against 4 .}

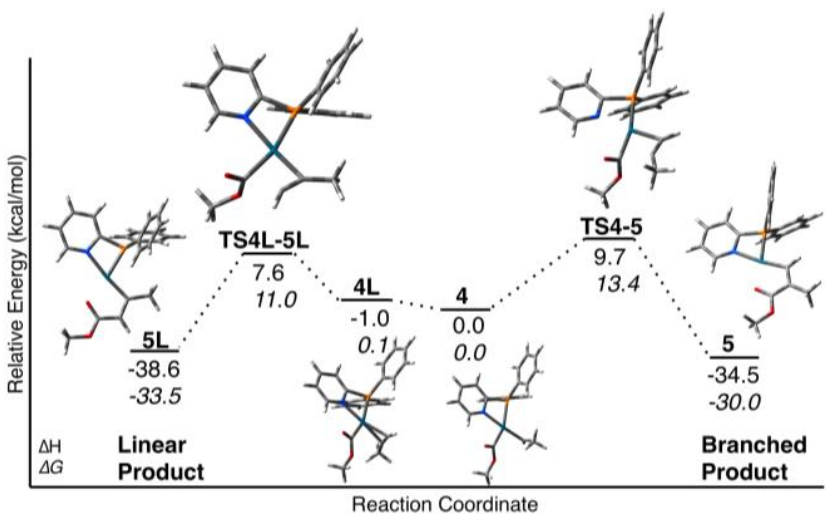

MMA-affording TS4-5 is $2.4 \mathrm{kcal} / \mathrm{mol}$ higher than that of MC producing TS4L-5L, leading to the surprising conclusion that 2,1 insertion is more favourable! The same is found for the mechanistic alternative with lower overall barrier (Scheme S2), where $\Delta \Delta \mathrm{G}^{\star}$ between TS4a-5a and TS4aL-5aL is 2.2 $\mathrm{kcal} / \mathrm{mol}$ (Scheme S3, ESI). Thus, if such a methoxycarbonylation route were operating under turnover conditions, $\mathrm{MC}$ should be produced with a high selectivity $(\approx 2 \%-3 \%$ branched product at $45^{\circ} \mathrm{C}$ ).

The unexpected 2,1 preference arises due to a clash of the propyne methyl with the ester substituent in the branchedforming route. In TS4L-5L, which has the terminal hydrogen of $\mathrm{HCCCH}_{3}$ towards the bulky carbomethoxy group, there is no such close contact and thus the linear-forming transition state is easier to access. Mechanism A can therefore be safely excluded because it affords the incorrect selectivity. 


\section{Scheme 7: Classical hydride mechanism beginning from an N-trans Pd-H species. TS12-13 is rate determining.}

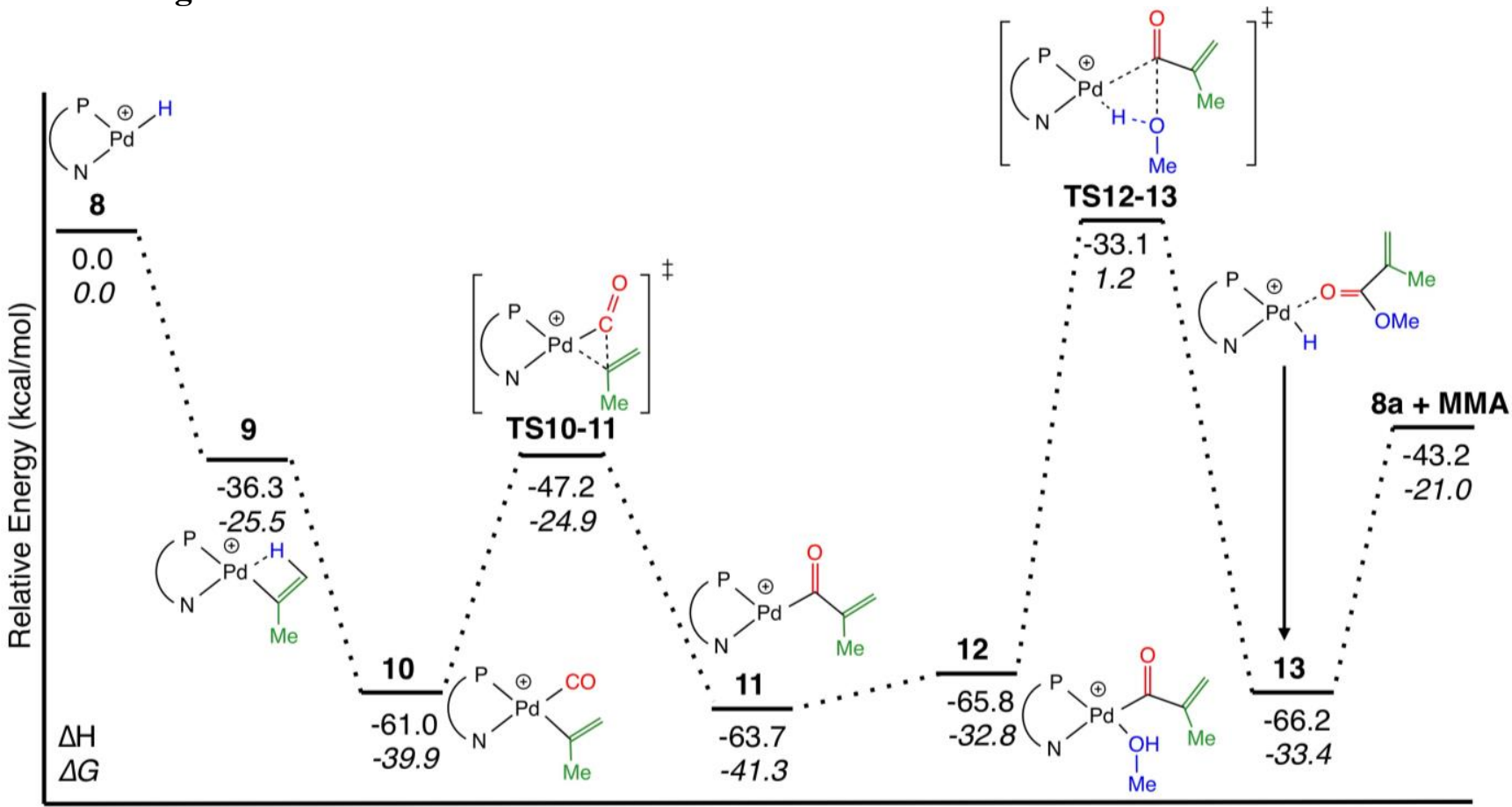

Reaction Coordinate

\section{2 - CLASSICAL HYDRIDE MECHANISM (B)}

We now turn to the classical hydride mechanism starting with $\mathrm{Pd}(\mathrm{II})$ hydride 8 (Scheme 7). Surprisingly, no stable intermediate with side-on coordinated alkyne, i.e. [( $\kappa^{1}-(2-$ $\left.\left.\left.\mathrm{PyPPh}_{2}\right)\right) \mathrm{Pd}(\mathrm{H})\left(\mathrm{HCCCH}_{3}\right)\right]^{+}$, could be located - irrespective of the binding mode of propyne (parallel or perpendicular to the H-Pd-chelate plane $)^{79}$. All attempts to optimize such structures result in spontaneous insertion, affording either the branched vinyl complex 9 or the linear analog 9L. The effect on selectivity is discussed below. Scans from the vinyl intermediates 9 and $9 \mathrm{~L}$ probing the reaction coordinate associated with the formative $\mathrm{C}-\mathrm{H}$ bond have been performed. On such a potential energy surface movement of the hydrogen from carbon back to palladium is observed but no stable minimum with a $\pi$-coordination mode of propyne can be located (see ESI, section S3). Thus it may be assumed that uptake of propyne would lead directly to either 9 or $9 \mathbf{L}$, controlled by approach trajectory and orientation.

Therefore, we have computed two reaction profiles, producing either MMA or MC. As with carbomethoxy mechanism A, the production of one MMA unit results in a different stereoisomer of the hydride and thus a full catalytic cycle producing two MMA units and switching the trans orientation of $\mathrm{P}$ and $\mathrm{N}$ of the $\kappa^{2}-\left(2-\mathrm{PyPPh}_{2}\right)$ chelate must be considered.

We have explored a route for interconversion between these two half-cycles via trigonal TS8-8a though this is found to be $47.5 \mathrm{kcal} / \mathrm{mol}$ uphill relative to $\mathbf{8}$, which, in turn, is more stable than $8 \mathbf{a}$ by $15.3 \mathrm{kcal} / \mathrm{mol}$. Such a simple path switching is thus excluded though we are aware that interconversion might be possible at different stages of the reaction (e.g. at 11) or through fluxional associative exchange of the 2-PyPPh ligand with one from the bulk ${ }^{36}$. Accordingly, we will limit our discussion to the lowest free-energy spans across individual half- cycles (Table S1) such as that with the most accessible methanolysis, illustrated in Scheme 7.

The rate-limiting barrier on path $\mathbf{B}$ is associated with terminating methanolysis, which has been found to be a difficult process in prior studies ${ }^{80,81,82}$. Over the whole pathway, the largest free energy barriers are predicted between 11a and TS12a-13a, namely $53.3 \mathrm{kcal} / \mathrm{mol}$ (MC forming) and 54.2 $\mathrm{kcal} / \mathrm{mol}$ (MMA forming, Table S1).

Even with path switching that would avoid this kinetic bottleneck, free energy barriers of at least $40.8 \mathrm{kcal} / \mathrm{mol}$ (MC forming) and $42.5 \mathrm{kcal} / \mathrm{mol}$ (MMA forming) are predicted (relative to the lowest preceding intermediate 11). Based on such evidence, this hydride path can already be discounted on energetic grounds.

Assessment of selectivity is difficult in this case as there is no barrier on the electronic surface for the irreversible 1,2 or 2,1 insertions between propyne and 8(a) on the potential energy surface. Entropic barriers may be expected due to the associative nature of these reactions but according to the BellEvans-Polyani principle the relative thermodynamic driving forces should govern these barriers and, thus, the selectivity. On the pathway showing the most accessible terminating methanolysis, that of Scheme 7, there is little distinction between 9 and MC-forming $\mathbf{9 L}$. The former is slightly more favourable in terms of enthalpy, by $0.5 \mathrm{kcal} / \mathrm{mol}$, while the latter is barely more stable by $0.1 \mathrm{kcal} / \mathrm{mol}$ in free energy as shown in Table 1. Little, if any, selectivity for MMA over MC would be expected, further disfavoring pathway $\mathbf{B}$.

To conclude, the classical hydride mechanism suffers from an essentially insurmountable intramolecular methanolysis step and cannot reproduce the observed selectivity. 


\section{Scheme 8: Carbomethoxy mechanism $\mathrm{C}$-II incorporating a $\mathbf{P}, \mathbf{N}$ ligand acting as a proton messen- ger (TS19-20). The rate - determining step is the migratory insertion of methoxide into carbon monoxide (TS16-17) and the selectivity is determined via TS18-19 that irreversibly leads to 19.}

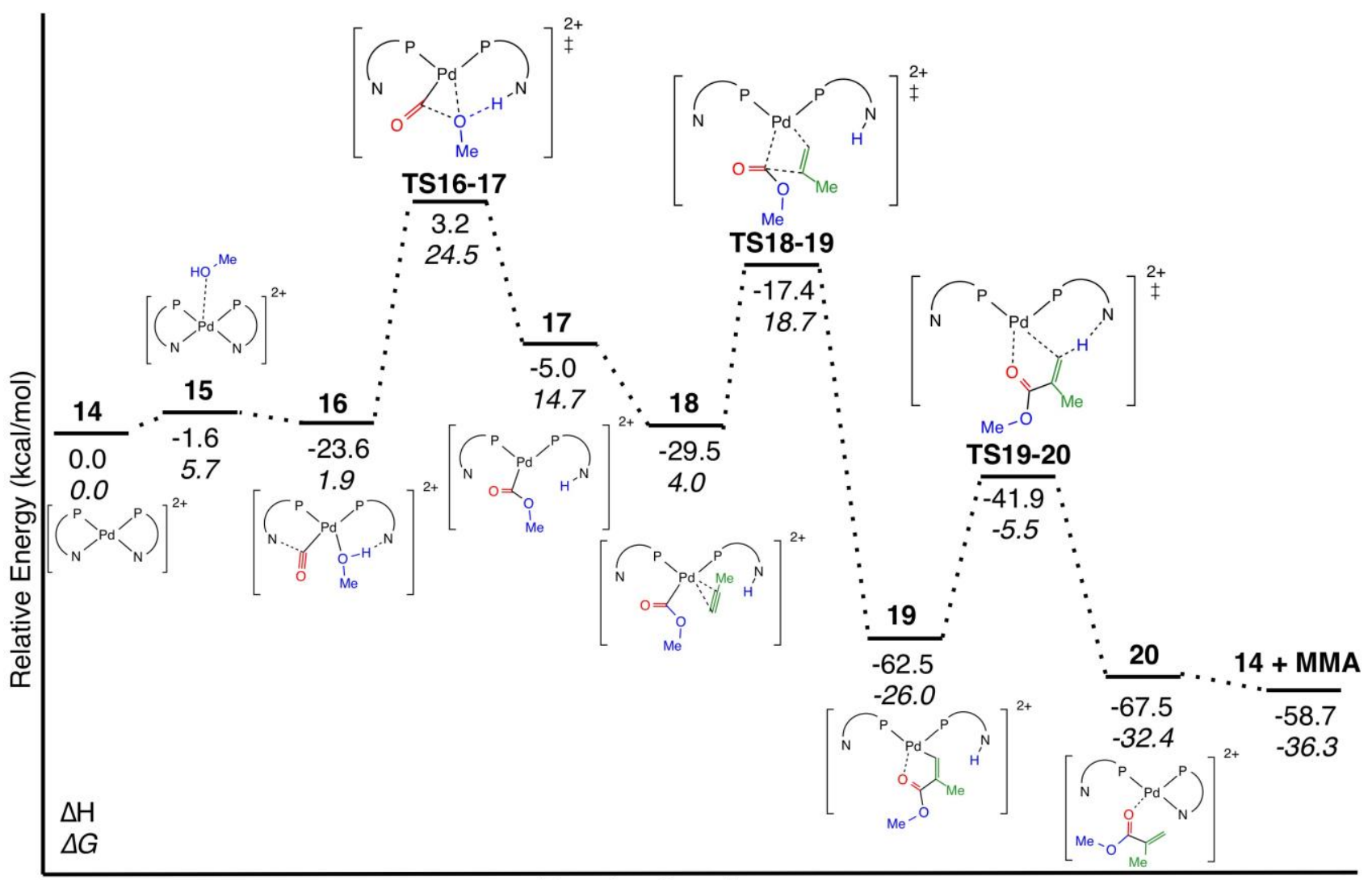

Reaction Coordinate

\section{3 - NON-CLASSICAL MESSENGER CARBOMETHOXY MECHANISMS (C AND C-II)}

Drent's original non-classical carbomethoxy mechanism $(\mathbf{C}$, Scheme 3) can be excluded because the proposed selectivity determining transition state is the same as in cycle A. Dervisi and co-workers proposed ${ }^{5,6}$ a mechanism for the production of MMA from $\left[\left(2-\mathrm{PyPPh}_{2}\right)_{2} \mathrm{Pd}\left(\mathrm{CO}_{2} \mathrm{R}\right)(\mathrm{OAc})\right]$ which incorporates two mono coordinating phosphine ligands. Increasing the quantity of both acid and phosphine leads to an observed zero order in acid and therefore any protonolysis step appears to involve 2- $\mathrm{PyPPh}_{2}$ acting as a relay. A possible adapted messenger carbomethoxy mechanism accounting for this experimental nuance, that incorporates two mono coordinating phosphines, C-II, is presented in Scheme 8.

The key difference between Drent's original carbomethoxy mechanism, $\mathbf{C}$, and the modified cycle we have investigated, C-II, is that the latter incorporates two 2-PyPPh 2 ligands throughout the reaction. Coordination of both methanol and carbon monoxide (affording 16) is exothermic, but essentially isoergonic with presumed resting state 14. The following transition state for concerted migratory insertion and deprotonation, TS16-17, emerges as the rate limiting state at 24.5 $\mathrm{kcal} / \mathrm{mol}$. Intermediate $\mathbf{1 7}$ is less favourable against both $\mathbf{1 4}$ or 16 (when considering free energy) and the resultant uptake of propyne leaves $184.0 \mathrm{kcal} / \mathrm{mol}$ above 14. All subsequent steps are exergonic with barriers of $20.5 \mathrm{kcal} / \mathrm{mol}$ (protonolysis via TS19-20) or less.

The irreversible regioselective transition state, TS18-19, produces a palladium-alkenyl intermediate leading to MMA. Compared to the analogous transition states in cycles $\mathbf{A}$ and $\mathbf{B}$, TS18-19 incorporates the greater steric bulk of the second phosphine ligand, the influence of which upon selectivity has been explored (Figure 2).

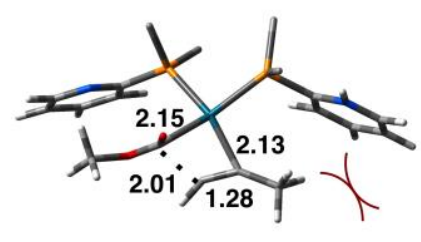

TS18L-19L

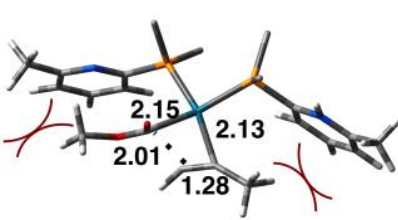

TS18L-19L 6-Me

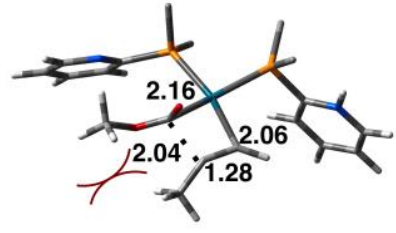

TS18-19

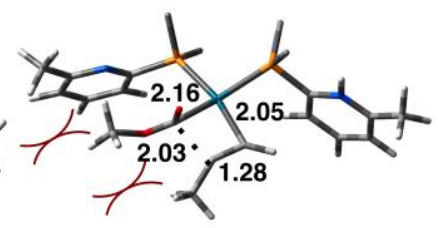

TS18-19 6-Me
Figure 2: MC (TS18L-19L) and MMA (TS18-19) forming transition states with 2- $\mathrm{PyPPh}_{2}$ (top) and 2-(6-Me) $\mathrm{PyPPh}_{2}$ (bottom). 
Distances in $\AA$ and $\mathrm{Ph}$ groups have been omitted for clarity. Steric clashes highlighted with red.

Energetically, the competing transition states do not show a difference that would be compatible with observed selectivity; TS18-19 is only $0.2 \mathrm{kcal} / \mathrm{mol}(\Delta \mathrm{G})$ more favourable than TS18L-19L, corresponding to a selectivity for MMA of approximately $73 \%$. The change in selectivity from a 2,1 mode in mechanism $\mathbf{A}$ to a 1,2 mode in $\mathbf{C}$-II arises because in the 2,1 process the methyl unit of propyne is orientated towards the pyridyl ring, invoking an unfavorable steric interaction. Despite this, such a clash is apparently not enough to reach the 99\% selectivity observed under turnover conditions.

Additional evidence against mechanism C-II emerges from the effect of 6-methylation of the pyridyl rings. While such a modification leads to an increase in selectivity towards MMA from $99 \%$ to $99.95 \%$ in practice, our density functional calculations with the added 6-Me groups fail to reproduce this noticeable change. In fact we find that the selectivity of mechanism C-II is reversed by 6-methylation as TS18-19 6-Me is $0.2 \mathrm{kcal} / \mathrm{mol}$ less favourable than TS18L-19L 6-Me! A closer inspection of the transition states given in Figure 2 provides some rationale for the low computed selectivity. The regioselective transition states in C-II have the pyridyl rings orientated such that the bulk (and the methyl modification) points away from the plane spanned by the metal and the $\mathrm{C}$ atoms involved in migratory insertion. Meanwhile, the clash between the carbomethoxy moiety and propyne methyl in the 1,2 mode is made more severe by the additional methyl unit on the pyridyl ring.

On the grounds of insufficient and incorrect regioselectivity ${ }^{83}$, both mechanisms $\mathbf{C}$ and $\mathbf{C}$-II can be excluded because experimental selectivities are not reproduced and subtle ligand effects are incorrectly accounted for. Full C-II energetics, including 2-(6-Me) $\mathrm{PyPPh}_{2}$, are given in the ESI, Table S2.

\section{4 - IN-SITU BASE MECHANISM (D)}

Scrivanti's Pd(0) mechanism (D, Scheme 3) involves formation of a $\mathrm{Pd}$-vinyl species ${ }^{7}$ through protonation of coordinated propyne ${ }^{8}$ with selectivity imbued during the proton transfer step involving a mono-coordinated $2-\mathrm{PyPPh}_{2}$ ligand acting as a proton-shuffling relay ${ }^{84-86}$. The precursor species could be $\left[\left(\kappa^{1}-\left(2-\mathrm{PyPPh}_{2}\right)\right)\left(\kappa^{1}-\left(2-\mathrm{PyHPPh}_{2}\right)\right) \mathrm{Pd}(\mathrm{CO})(\mathrm{HCCMe})\right]^{+}$ $(21+\mathrm{CO})$ with a concerted protonation and migratory insertion yielding a palladium-acyl intermediate(Scheme 4$)^{1}$. This complex, 21+CO, with the expected tetrahedral geometry was identified as being slightly exergonic relative to $\mathbf{2 1}$ and this led us to start the reaction from the more stable planar complex $\left[\left(\kappa^{1}-\left(2-\mathrm{PyPPh}_{2}\right)\right)\left(\kappa^{1}-(2-\mathrm{PyHPPh})\right) \mathrm{Pd}(\mathrm{HCCMe})\right]^{+}$. The possibility of a $\left[\left(\kappa^{2}-\left(2-\mathrm{PyPPh}_{2}\right)\right)\left(\kappa^{1}-\left(2-\mathrm{PyPPh}_{2}\right)\right) \mathrm{Pd}(\mathrm{H})\right]^{+}$species being catalytically relevant was also assessed and calculations excluding a route involving such an intermediate are included in the ESI, Scheme S5.

The first transformation that $\mathbf{2 1}$ must undergo is regioselective ligand-assisted protonation as detailed in Scheme 9. Protonation of the alkyne via TS21-22 needs only $7.2 \mathrm{kcal} / \mathrm{mol}$ of activation energy and establishes a co-catalytic role of $\mathrm{P}, \mathrm{N}$ as an agent for accessible proton transfer. We attempted to locate a transition state such as that outlined in Scheme 4 though ultimately could not characterize such a concerted process. Instead an alternative pathway of $\mathbf{2 1 + C O}$ undergoing a stepwise protonation, similar to that discussed for $\mathbf{2 1}$, with $\mathrm{CO}$ remaining coordinated throughout became apparent. Following insertion, this route leads directly to $\mathbf{2 4}$ but the activation cost of the proton transfer transition state, TS21+CO-24, is higher (by $\Delta \Delta \mathrm{G}^{*}=3.8 \mathrm{kcal} / \mathrm{mol}$ ) than that offered by TS21-22. For further details on this process see the ESI, section S5.
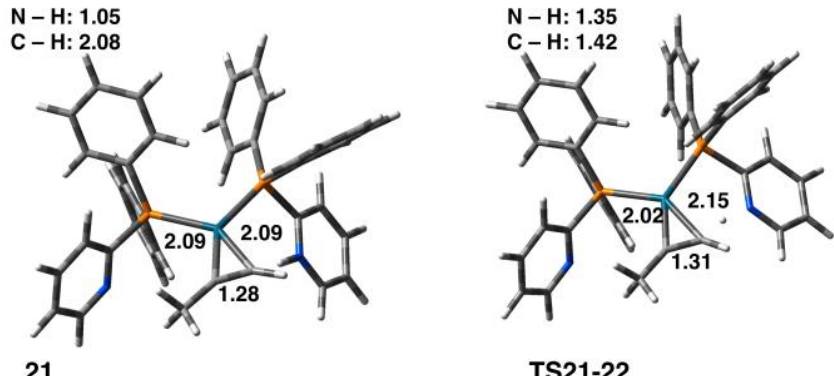

21

TS21-22

Pd-Alkenyl: 2.07

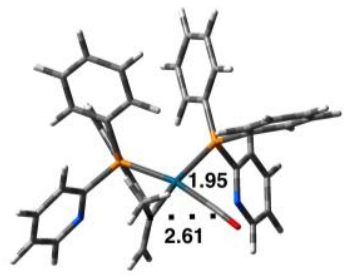

24

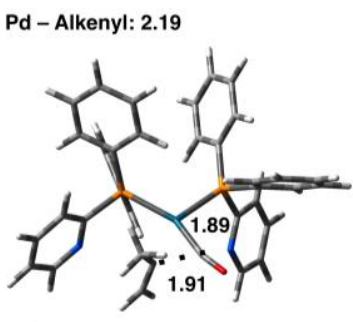

TS24-25

Figure 3: Intermediates and TS involved in carbonylation of propyne during Mechanism D. Distances in $\AA$.

Key intermediates and transition states of the initial carbonylation steps are displayed in Figure 3. 21 displays strong backbonding between palladium and propyne with $\mathrm{Pd}-\mathrm{C}$ distances of $2.07 \AA$. TS21-22 is followed by a series of energetically downhill steps from $\beta$-agostic intermediate 22, yielding 24 (Figure 3) following displacement of a chelating binding mode in $\mathbf{2 3}$ via $\mathrm{CO}$ uptake. Regioselective insertion is therefore practically irreversible under experimental conditions and this is essential to the high selectivities (discussed below) observed by preventing dynamic communication of branched and linear intermediates.

The migratory insertion into the metal-carbon bond via TS24-25 is easily surmountable, being only $10.3 \mathrm{kcal} / \mathrm{mol}$ uphill from the prior intermediate and is encouraged by formation of a Pd-acyl complex. The now-deprotonated pyridyl acts as an intermittent chelate, stabilizing intermediates that would otherwise be coordinatively unsaturated. Wiberg Bond Index $(\mathrm{WBI})^{87}$ measurements show a significant sharing of electron density between bond-forming carbon centers $(0.12)$ in 24, accounting for the ease of this transformation.

Unlike the proton transfer steps, $\mathrm{CO}$ insertion is reversible with an activation free energy of $10.3 \mathrm{kcal} / \mathrm{mol}$ and a backward cost of $16.4 \mathrm{kcal} / \mathrm{mol}$ - notably lower than the barrier we compute for methanolysis (Scheme 10). However, as the prior propyne insertion step remains irreversible, the reversibility of $\mathrm{CO}$ insertion will not affect the overall regioselectivity. Following carbonylation a terminating alcoholysis step is necessary to yield MMA. Unlike hydride mechanism $\mathbf{B}$ this process does not require the costly step of an alcoholic proton being transferred to a $\mathrm{Pd}(\mathrm{II})$ center but can rather involve the 2$\mathrm{PyPPh}_{2}$ ligand, reprotonating the pyridyl moiety. As demonstrated in Scheme 10, incorporation of the pyridyl as an in-situ base offers a far more accessible route. 
Scheme 9: Initial proton transfer and carbonylation at $\mathrm{Pd}(0)$ with two mono-coordinated 2$\mathrm{PyPPh}_{2}$ units. TS21-22 imbues regioselectivity.

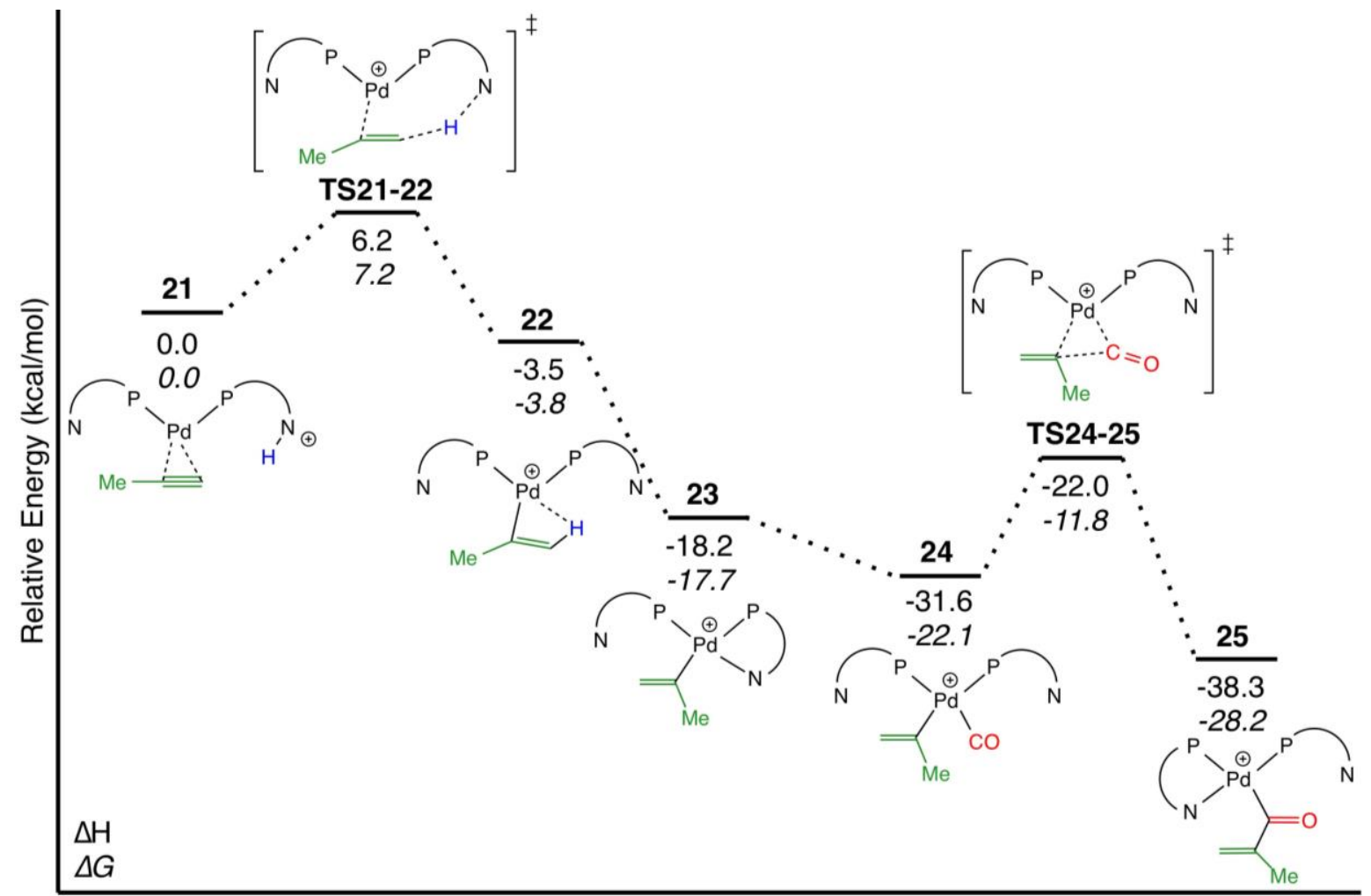

Reaction Coordinate

Scheme 10: Terminating methanolysis to yield MMA. Energies presented relative to 21. The ratelimiting step is solvolysis (TS26-27) while the overall cycle is thermodynamically driven.

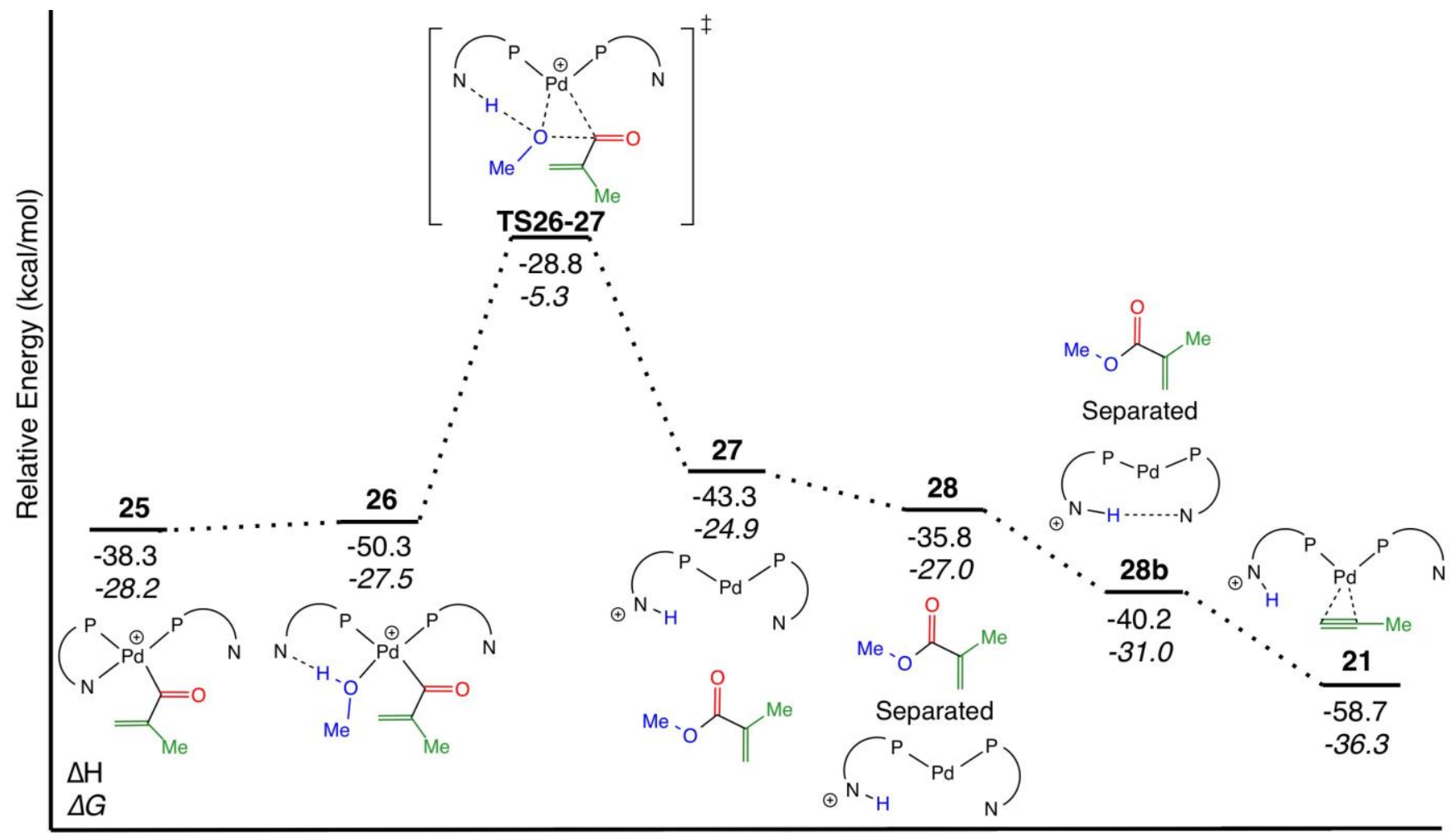


We note that one limitation of our computations is in the use of a PCM to account for bulk solvation. Methanol molecules in the second coordination sphere around $\mathbf{2 6}$ may play a role in accepting and transferring the proton arising from deprotonation away from the Pd center. This would serve to lower the free energy cost of the process with an entropic gain from distribution and an enthalpic gain from additional hydrogen bonding. However, since a 2-PyPPh 2 unit must be reprotonated in order to conduct regioselective propyne insertion at $\mathbf{2 1}$, we have not explored this route further.

Displacing chelating 2-PyPPh and binding methanol is slightly endergonic, though by only $0.7 \mathrm{kcal} / \mathrm{mol}$. Reaction entropies for such associative processes are often overestimated by our standard protocol and it is worth noting that binding is found to be exothermic by $12 \mathrm{kcal} / \mathrm{mol}$ (see $\Delta \mathrm{H}$ values in Scheme 10). This methanol coordination preferentially occurs such that the hydroxyl unit orientates its proton towards the basic nitrogen of 2- $\mathrm{PyPPh}_{2}$ resulting in the nucleophilic oxygen and acyl carbon being separated by $2.71 \AA$ (Figure 4). Establishing this intramolecular hydrogen bond with a close distance of $1.65 \AA$ between nitrogen and hydrogen is key in facilitating methanolysis through TS26-27. With a $\Delta G^{\ddagger}$ of $22.9 \mathrm{kcal} / \mathrm{mol}$ relative to $\mathbf{2 5}$ this is considerably more accessible than the related solvolysis process in mechanism $\mathbf{B}$, which requires a barrier exceeding $40 \mathrm{kcal} / \mathrm{mol}$.

In this transition state coordinated methanol is deprotonated by the co-catalytic 2-PyPPh ligand and the transient methoxide attacks the $\mathrm{Pd}-\mathrm{C}_{(\text {acyl) }}$ bond. Since the MMA product immediately dissociates away from the primary coordination sphere (28 / 28b) this step is characterized as reductive elimination. Here, the $\mathrm{P}, \mathrm{N}$ ligand demonstrates its second cocatalytic property as an in-situ base, which is essential for the high performance of methoxycarbonylation. Subsequent uptake of propyne to reform $\mathbf{2 1}$ provides the final driving force for closing the catalytic cycle. TS26-27 also rationalizes why $2-\mathrm{PyPPh}_{2}$ has much greater activity than $3-\mathrm{PyPPh}_{2}{ }^{2,3}$. In the latter, the orientation of the nitrogen lone pair would not allow for formation of the intramolecular hydrogen bond in $\mathbf{2 6}$ and the ability of pyridyl to act as a co-catalyzing base is decreased.

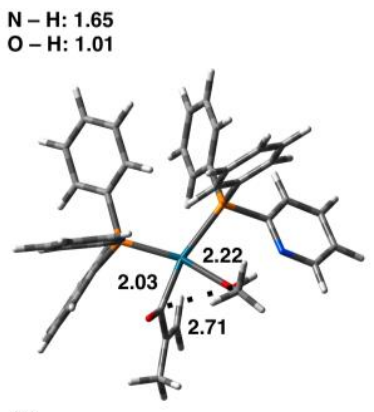

26

Figure 4: Geometries associated with MMA producing methanolysis of Pd-acyl species in mechanism D. Distances are given in $\AA$.

The MC-forming methanolysis step is of little importance to the overall regioselectivity of the methoxycarbonylation within this reaction mechanism. Even if it is more favourable as a result of lesser steric constraints for reductive elimination of the linear acyl, it will not affect the ultimate product distribution as this is determined by the irreversible propyne insertion step, the selectivity of which we now explore.

\section{1 - SELECTIVITY OF THE IN-SITU BASE MECHANISM}

The linear forming route through TS21L-22L was compared to the branched-forming TS21-22 (Scheme 11). Thermodynamically, the intermediate which leads to MMA formation (23) is favourable over that leading to MC (23L) and furthermore the associated saddle point (TS21-22) is more accessible than TS21L-22L. The free energy difference between the kinetic barriers for these processes is $2.2 \mathrm{kcal} / \mathrm{mol}$ - a selectivity towards MMA of $98 \%$ at $25{ }^{\circ} \mathrm{C}$ and $97 \%$ at $45{ }^{\circ} \mathrm{C}$ that is inline with experimental observations. A concern that had led to the proposal of the concerted pathway ${ }^{1}$ outlined in Scheme 4 was the expectation that an alkenyl intermediate with bulk $\alpha$ to Pd would be less favourable than the linear alternative. Calculations show that the isomeric products are in fact almost equivalent in free energy and the branched transition state does not stifle proton transfer.

\section{Scheme 11: Selectivity determining transition states for mechanism $D$.}

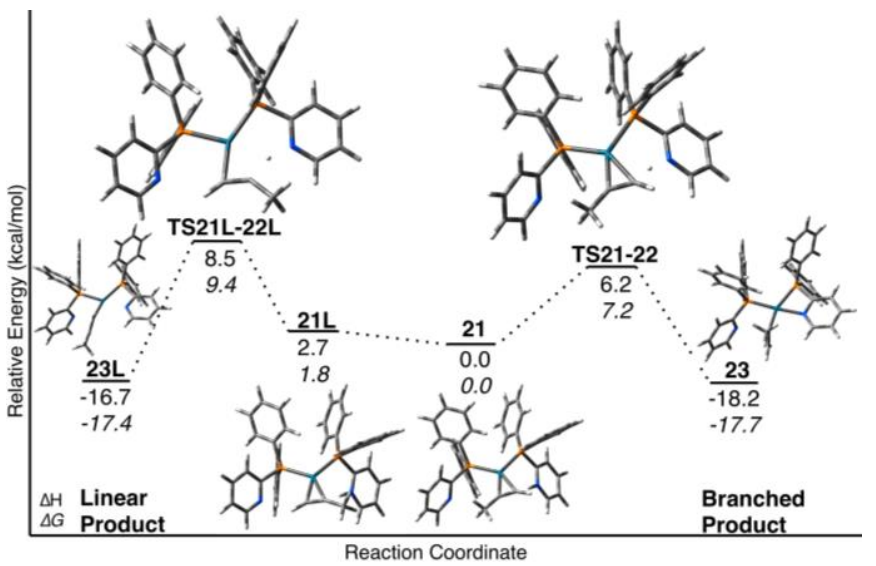

Regioselectivity is controlled by steric effects as in delivering a proton the pyridyl moiety moves into the plane of the $\pi$ coordinated propyne (Scheme 11). In TS21-22 there are no severe clashes however in the MC-forming TS21L-22L this movement introduces a more pronounced interaction between the pyridyl ring and the methyl group of propyne, resulting in a higher barrier. Interestingly, the irreversible propyne insertion step can be viewed as equivalent to a Markovnikov addition of a strong acid, [(2-PyPPh$\left.\left.{ }_{2}\right) \mathrm{Pd}\left(2-\mathrm{PyPPh}_{2} \mathrm{H}\right)\right]^{+}$, to an alkyne. In this analogy, the regioselectivity follows that of protonation at the least substituted carbon of propyne, yielding the Markovnikov product while the anti-Markovnikov process is less favourable in both kinetics and thermodynamics.

Table 1 reports the free energies governing turnover and selectivity for ligand systems 2-PyPPh and 2-(6-Me) $\mathrm{PyPPh}_{2}$ within path D. Species $\mathbf{2 2}$ and $\mathbf{2 8} / \mathbf{2 8 b}$ are not presented due to their negligible impact on the reaction profile. We detail the selectivities of the less favourable mechanistic alternative from $\mathbf{2 1 + C O}$ to $\mathbf{2 4}$ in ESI Table S3, noting here that this route is favourable for MMA production over MC. A comparison of these energies shows that 6-methylation results in improved selectivity for MMA against MC with $\Delta \Delta \mathrm{G}^{\star}$ increasing from $2.2 \mathrm{kcal} / \mathrm{mol}$ to $4.1 \mathrm{kcal} / \mathrm{mol}$, arising from a subtle ligand effect. 
Table 1: Comparative reaction profiles $(\Delta \mathrm{G}, \mathrm{kcal} / \mathrm{mol})$ for methoxycarbonylation of propyne under differing experimental conditions. Enthalpies are given in Table S4 within the ESI.

\begin{tabular}{|c|c|c|c|c|c|c|c|}
\hline$\underline{\Delta G}$ & $\underline{21}$ & $\underline{\text { TS21-22 }}$ & $\underline{23}$ & & $\underline{21 L}$ & TS21-22L & $\underline{23 \mathrm{~L}}$ \\
\hline 2-PyPPh & 0.0 & 7.2 & -17.7 & & 1.8 & 9.4 & -17.4 \\
\hline 2-(6-Ме)PyPPh & 0.0 & 9.0 & -14.7 & & 1.2 & 13.1 & -15.4 \\
\hline \multirow[t]{2}{*}{ 2-PyPPh 2 dicat. } & 0.0 & 10.3 & -14.2 & & 1.3 & 13.4 & -12.4 \\
\hline & $\underline{24}$ & $\underline{\text { TS24-25 }}$ & $\underline{25}$ & $\underline{26}$ & $\underline{\text { TS26-27 }}$ & $\underline{27}$ & $\underline{21+\text { MMA }}$ \\
\hline 2-PyPPh & -22.1 & -11.8 & -28.2 & -27.5 & -5.3 & -24.9 & -36.3 \\
\hline 2-(6-Мe)PyPPh & -20.6 & -10.3 & -25.1 & -26.1 & -3.7 & -25.3 & -36.3 \\
\hline 2-PyPPh ${ }_{2}$ dicat. & -14.1 & -5.2 & -24.9 & -24.3 & -4.8 & -24.8 & -36.3 \\
\hline
\end{tabular}

Table 2: Mechanisms relevant to the methoxycarbonylation of propyne by $\operatorname{Pd}(P, N)_{n}$ systems under the scrutiny of the energetic span model. Computed at $\mathrm{T}=\mathbf{2 9 8 . 1 5} \mathrm{K}$.

\begin{tabular}{|c|c|c|c|c|}
\hline Mechanism & $\underline{\text { TOF (relative) }}$ & $\underline{\text { MARI }}$ & $\underline{\text { HETS }}$ & $\underline{E n e r g y ~ S p a n ~}^{2}$ \\
\hline$A(\text { full } 1->1 a->1)^{b}$ & 1 & 5 & TS6-7 & 38.0 \\
\hline$A(\text { partial 1a }->1 a)^{c}$ & $4.9 \times 10^{4}$ & $5 a$ & TS6a-7a & 31.2 \\
\hline B (full $8->8 a->8)^{b}$ & $1.3 \times 10^{-11}$ & 11 & TS12-13 & 54.2 \\
\hline$B(\text { partial 8a }->8 a)^{c}$ & $2.3 \times 10^{-4}$ & $11 \mathrm{a}$ & TS12a-13a & 42.5 \\
\hline C-II & $3.8 \times 10^{9}$ & 14 & TS16-17 & 24.5 \\
\hline D & $4.5 \times 10^{10}$ & 25 & TS26-27 & 22.9 \\
\hline D - 6Me & $1.2 \times 10^{11}$ & 26 & TS26-27 & 22.4 \\
\hline D - Dication & $4.9 \times 10^{12}$ & 25 & TS26-27 & 20.1 \\
\hline
\end{tabular}

${ }^{a}$ Free-energy difference in $\mathrm{kcal} / \mathrm{mol}$ between the MARI (most abundant reaction intermediate) and HETS (highest energy transition state). ${ }^{b}$ Full cycle producing 2 equivalents of MMA. ${ }^{c}$ Half cycle with lower energy span producing 1 equivalent of MMA and assuming rapid interconversion between $\mathbf{1}$ and $\mathbf{1 a}$ or $\mathbf{8}$ and $\mathbf{8 a}$ as applicable.

\section{2 - IMPACT OF ACIDIC CONDITIONS}

Finally, we turn to the effect of strongly acidic conditions that are essential for achieving expedient turnover. Under such conditions (and because the $p \mathrm{~K}_{\mathrm{b}}$ values of the two remote pyridine bases within the same complex are expected to be very similar) not only one but both pyridyl groups may be protonat$\mathrm{ed}^{8}$. We have thus repeated all calculations summarized in Schemes 9 and 10 for diprotonated, dicationic complexes and the resulting free energies are included in Table 1 (see 2$\mathbf{P y P P h}_{2}$ dicat. entries). According to these data, not only does a dicationic equivalent improve selectivity with $\Delta \Delta \mathrm{G}^{\sharp}$ between regioselective transition states increasing to $3.1 \mathrm{kcal} / \mathrm{mol}$ but, crucially, the methanolysis barrier is also reduced to 20.1 $\mathrm{kcal} / \mathrm{mol}$

Greater regioselectivity arises from protonation removing the weak interaction between basic pyridyl nitrogen and acidic propyne hydrogen in TS21L-22L, which can be seen at the left hand side of Scheme 11. In the protonated congener of this transition state, the previously basic nitrogen now presents a partially positive hydrogen and the pyridyl group rotates to avoid an unfavorable electrostatic interaction with coordinated propyne. This protonation and subsequent reorientation removes a polarizing interaction that reduces the effective barrier of TS21L-22L in the monocationic 2-PyPPh ${ }_{2}$ system and therefore diprotonation leads to enhanced selectivity for MMA.

Excess acid also positively impacts turnover by decreasing the rate limiting solvolysis barrier to $20.1 \mathrm{kcal} / \mathrm{mol}$. In a dicationic system, the previously basic nitrogen lone pair of the non-participating pyridyl is now replaced by an acidic $\mathrm{N}-\mathrm{H}^{+}$ functionality, which accelerates methanolysis by forming an intramolecular H-bond to the acyl carbon (right hand side in Figure 5).

This is confirmed by analysis of the Natural Population Analysis (NPA) charges and geometries at the methanolysis transition states. On going from the mono- to the dicationic system, the $\mathrm{O}_{\text {(methanol) }}-\mathrm{C}_{\text {(acyl) }}$ separation increases from $1.71 \AA$ to $1.81 \AA$, consistent with an earlier transition state, and the acyl group becomes more negative (see the NPA charges in Figure 5), facilitating methanolysis.
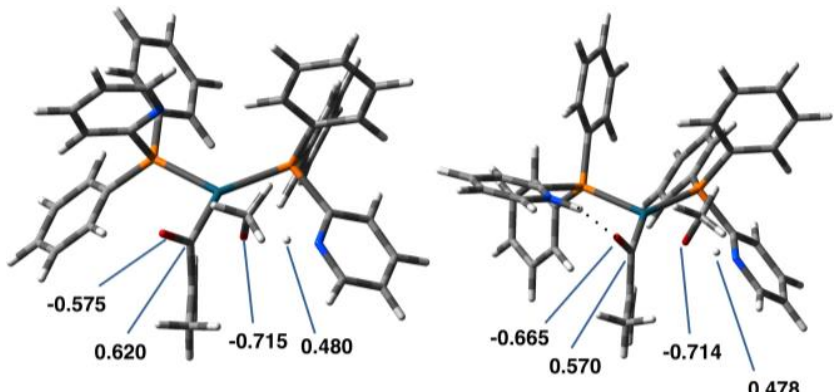

Figure 5: Transition states for the monocationic methanolysis TS26-27 (left) and dicationic analog (right). NPA charges on key atoms are included to highlight the different charge distributions.

\section{5 - ANALYSIS OF MECHANISMS A TO D - INTERPRETATION THROUGH ENERGETIC SPAN}

The energetic span model of Kozuch and Shaik ${ }^{88-90}$ allows for the calculation of turn over frequencies (TOFs) from computed free energy values of reactants, intermediates, transition 
states and products. This prescription further affords detail of the most abundant reaction intermediates (MARIs) and the highest energy transition state (HETS) that maximize the energetic span along one complete cycle and exert kinetic control on the propensity of the reaction.

While absolute TOF values are associated with the usual uncertainties of simple transition state theory, relative TOF values can afford insight into the preferred reaction channels of competing mechanisms. Table 2 reports the relative TOFs of all computed profiles, taken against mechanism $\mathbf{A}$, and additionally identifies the MARIs and HETS for each reaction channel. A (full) and B (full) have had their TOFs multiplied by two, as these cycles produce two equivalents of MMA.

In keeping with the free-energy barriers discussed previously the computed TOFs cover a large span - more than 23 orders of magnitude. Compared to the highest TOF obtained for the dicationic variant of pathway $\mathbf{D}$ (penultimate entry in Table 2), mechanisms $\mathbf{A}$ and $\mathbf{B}$ show negligible turnover. This conclusion is relevant regardless of whether the full paths have to be completed or shortcuts are available that could bypass the highest barriers (cf. the discussion in sections 1 and 2 above). Mechanism C-II, like D - Dication a dicationic pathway, is barely competitive with the latter, with relative turnover predicted to be three orders of magnitude lower.

Pathway D with its tenfold increase in TOF over C-II and the correct selectivity is clearly the most plausible mechanism. Crucially, D and D - 6Me remain within an order of magnitude, which is inline with experiment. The TOF of pathway D is still two orders of magnitude below that of $\mathbf{D}$ - Dication but in practice both will operate simultaneously, depending on the precise position of the protonation equilibria, and an intermediate TOF will be observed. Therefore an in-situ base mechanism is the most likely one at this point and the key intermediates and transition states, prime targets for rational catalyst design, are identified as $\mathbf{2 5}$ / 26 and TS26-27 respectively.

\section{CONCLUSIONS}

We have studied four of the most likely mechanisms for MMA production at Pd catalysts with $\mathrm{P}, \mathrm{N}$ ligand systems. Our computations show that a typical carbomethoxy mechanism (A) cannot account for selectivity or turnover. Likewise, a hydride mechanism (B) can be excluded because it would suffer deactivation as a result of a particularly high barrier for intramolecular methanolysis.

Drent's original messenger carbomethoxy route $(\mathbf{C})$ was proposed to operate via the same selectivity determining transition state as that of $\mathbf{A}$ which we have shown exhibits a preference for MC over MMA and we are confident in excluding this route. Dervisi proposed a similar mechanism that we have adapted to operate through a dicationic pathway. This mechanism, C-II, always contains two 2- $\mathrm{PyPPh}_{2}$ units and displays promising barriers and reasonable selectivity should the $\mathrm{Pd}$ OMe species be available under turnover conditions. However, this mechanism fails to reproduce the observed increase in selectivity for the 6-methylated analog and can thus be discounted.

The preferable pathway is $\mathbf{D}$, a $\operatorname{Pd}(0)$ in-situ base mechanism with hemilabile and co-catalytic 2-PyPPh 2 ligands, and/or a dicationic variant thereof (Scheme 12). While we could not confirm a concerted protonation and migratory insertion step that had been proposed recently ${ }^{1}$, we were able to characterize a stepwise pathway, beginning with a regioselective and irreversible protonation of coordinated propyne and terminating via $\mathrm{P}, \mathrm{N}$ assisted methanolysis. With both $2-\mathrm{PyPPh}_{2}$ and 2-(6$\mathrm{Me}) \mathrm{PyPPh}_{2}$ ligand systems, this catalytic cycle exhibits a selectivity for the branched-forming route that is completely congruent with experimental observations. Calculations show that the P,N system is strikingly different from other ligands used in catalytic carbonylation at Pd. Typically, these concern bidentate diphosphine backbones and give high selectivities towards linear (alkoxy)carbonylation products ${ }^{35,91-93}$. By contrast, 2-PyPPh $\mathrm{Ph}_{2}$ and congeners undergo an alternative "Pd - H" cycle and it is the unique mechanistic inclusion of the cocatalytic pyridyl moiety in regioselective proton transfer that enables this framework to conduct an alternative selectivity and favor branched products over linear. We have been able to identify the subtle ligand effects that dictate why the 6methylated analogue exhibits enhanced selectivity and can trace the requirement of acidic conditions back to the involvement of at least one, but possibly two, hemilabile 2$\mathrm{PyPPh}_{2}$ ligands protonated at the free nitrogen atoms during a mono-coordinating mode.

Scheme 12: Catalytic cycle of mechanism D involving an in-situ base, as emerging from our DFT calculations.

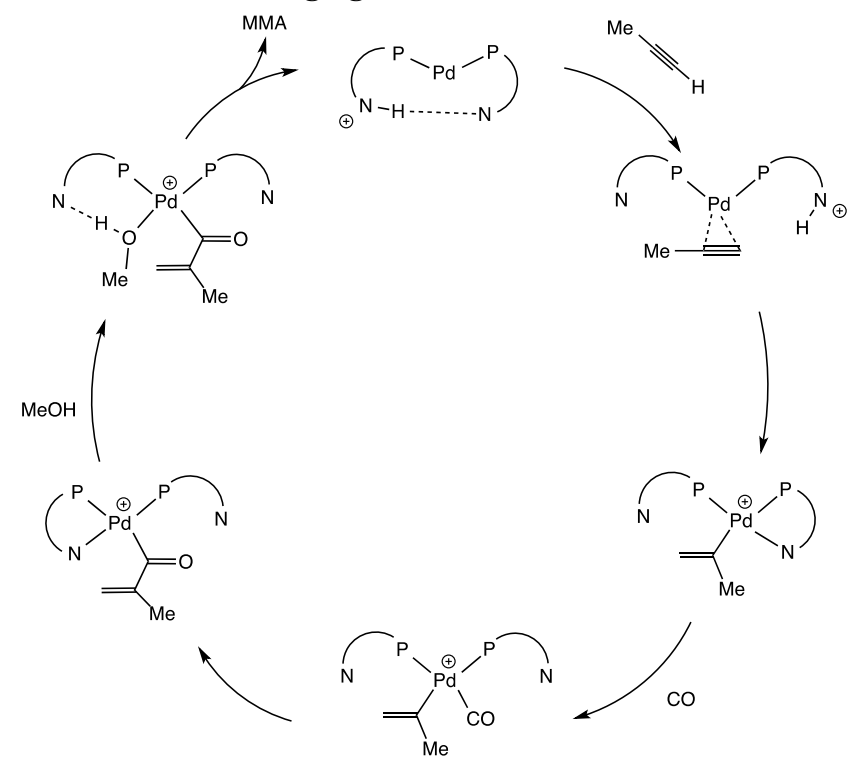

A diprotonated dicationic system is indicated to have the lowest overall barrier (for rate-determining methanolysis) and improving the accessibility of the solvolysis transition state has been outlined as a potential target for directed design.

We are hopeful that our detailed computational insights, which account for reactivities and selectivities at an atomistic level, will spur the development of new generations of more active and more selective catalyst systems for this important feedstock molecule. We have already proposed a simple ligand modification that should lower the turnover-determining barrier $^{51}$ and further studies along these lines are in progress.

\section{ASSOCIATED CONTENT}

\section{Supporting Information}

Model studies, additional energies for variants of mechanisms A D, XYZ coordinates of all complexes and small molecules and 
keywords employed are included. This material is available free of charge via the Internet at http://pubs.acs.org

\section{AUTHOR INFORMATION}

\section{Corresponding Author}

*E-mail for M.B.: buehl@st-andrews.ac.uk

Notes

The authors declare no completing financial interest.

\section{Acknowledgements}

The authors would like to thank the University of St. Andrews School of Chemistry and EaStCHEM for support and for access to a computing facility maintained by Herbert Früchtl. We also thank Professor Eite Drent for key discussions and suggestions.

\section{REFERENCES}

(1) Cole-Hamilton, D. J.; Drent, E. Alkyne Carbonylation. In Applied Homogeneous Catalysis with Organometallic Complexes; Cornils, B., Hermann, W. A., Beller, M., Paciello, R., Eds.; Wiley-VCH: Weinheim, Germany, 2014.

(2) Drent, E.; Arnoldy, P.; Budzelaar, P. H. M. J. Organomet. Chem. 1993, 455, 247.

(3) Drent, E.; Arnoldy, P.; Budzelaar, P. H. M. J. Organomet. Chem. 1994, $475,57$.

(4) Dervisi, A.; Edwards, P. G.; Newman, P. D.; Tooze, R. P.; Coles, S. J.; Hursthouse, M. B. J. Chem. Soc. Dalt. Trans. 1998, 1, 3771.

(5) Dervisi, A.; Edwards, P. G.; Newman, P. D.; Tooze, R. P.; Coles, S. J.; Hursthouse, M. B. J. Chem. Soc. Dalt. Trans. 1999, 3, 1113.

(6) Dervisi, A.; Edwards, P. G.; Newman, P. D.; Tooze, R. P. J. Chem. Soc. Dalt. Trans. 2000, 523.

(7) Scrivanti, A.; Beghetto, V.; Campagna, E.; Zanato, M.; Matteoli, U. Organometallics 1998, 17, 630.

(8) Scrivanti, A.; Bertoldini, M.; Beghetto, V.; Matteoli, U.; Venzo, A. J. Organomet. Chem. 2009, 694, 131.

(9) Raj, P. A.; Dentino, A. R. Future Med. Chem. 2013, 5, 1635.

(10) Harris, B. Ingenia 2010, 18.

(11) Moukwa, M. Chem. World 2010, 50

(12) De Pater, J. J. M.; Maljaars, C. E. P.; de Wolf, E.; Lutz, M.; Spek, A.

L.; Deelman, B.-J.; Elsevier, C. J.; van Koten, G. Organometallics 2005, 24,5299 .

(13) Consorti, C. S.; Ebeling, G.; Dupont, J. Tetrahedron Lett. 2002, 43, 753 .

(14) Michalak, A.; Ziegler, T. Top. Organomet. Chem. 2005, 12, 145.

(15) Troegel, D.; Stohrer, J. Coord. Chem. Rev. 2011, 255, 1440.

(16) Vougioukalakis, G. C.; Grubbs, R. H. Chem. Rev. 2010, 110, 1746.

(17) Abram, U.; Alberto, R.; Dilworth, J. R.; Zheng, Y.; Ortner, K. Polyhedron 1999, 18, 2995.

(18) Helmchen, G.; Pfaltz, a. Acc. Chem. Res. 2000, 33, 336

(19) Dedieu, A.; Rohmer, M.; Rettig, S. J. Organometallics 2001, 20, 2966.

(20) Felicissimo, M. P.; Batista, A. A.; Ferreira, A. G.; Ellena, J.; Castellano, E. E. Polyhedron 2005, 24, 1063.

(21) Chang, Y.; Lin, C.; Wang, S.; Liao, F. J. Organomet. Chem. 1999, 588,160 .

(22) Standfest-Hauser, C.; Slugovc, C.; Mereiter, K.; Schmid, R.; Kirchner, K.; Xiao, L.; Weissensteiner, W. J. Chem. Soc. Dalt. Trans. 2001, 2989.

(23) Wajda-Hermanowicz, K.; Ciunik, Z.; Kochel, A. Inorg. Chem. 2006, 45,3369 .

(24) Wasserman, H. J.; Moody, D. C.; Paine, R. T.; Ryan, R. R.; Salazara, K. V. Chem. Commun. 1984, 3, 533.

(25) Alcock, N. W.; Moore, P.; Lampe, P. A.; Mok, K. F. J. Chem. Soc. Dalt. Trans. 1982, 207.

(26) Olmstead, M. M.; Maisonnat, A.; Farr, J. P.; Balch, A. L. Inorg.

Chem. 1981, 4060.

(27) Flapper, J.; Wormald, P.; Lutz, M.; Spek, A. L.; van Leeuwen, P. W. N. M.; Elsevier, C. J.; Kamer, P. C. J. Eur. J. Inorg. Chem. 2008, 2008, 4968.
(28) Govindaswamy, P.; Carroll, P. J. J. Chem. Sci. 2006, 118, 319. (29) Furst, M. R. L.; Goff, R. Le; Quinzler, D.; Mecking, S.; Botting, C. H.; Cole-Hamilton, D. J. Green Chem. 2012, 14, 472.

(30) Furst, M. R. L.; Seidensticker, T.; Cole-Hamilton, D. J. Green Chem. 2013, 15, 1218

(31) Clegg, W.; Eastham, G. R.; Elsegood, M. R. J.; Tooze, R. P.; Wang, X. L.; Whiston, K. Chem. Commun. 1999, 1877.

(32) Clegg, W.; Eastham, G. R.; Elsegood, M. R. J.; Heaton, B. T.; Iggo, J. A.; Tooze, R. P.; Whyman, R.; Zacchini, S. Organometallics 2002, 21, 1832.

(33) Van Leeuwen, P. W. N. M.; Zuideveld, M. a; Swennenhuis, B. H. G.; Freixa, Z.; Kamer, P. C. J.; Goubitz, K.; Fraanje, J.; Lutz, M.; Spek, A. L. J. Am. Chem. Soc. 2003, 125, 5523.

(34) Fanjul, T.; Eastham, G.; Fey, N.; Hamilton, A.; Guy Orpen, A.; Pringle, P. G.; Waugh, M. Organometallics 2010, 29, 2292.

(35) Núñez Magro, A. A.; Robb, L.-M.; Pogorzelec, P. J.; Slawin, A. M. Z.; Eastham, G. R.; Cole-Hamilton, D. J. Chem. Sci. 2010, 1, 723.

(36) Liu, J.; Jacob, C.; Sheridan, K. J.; Al-Mosule, F.; Heaton, B. T.; Iggo, J. A.; Matthews, M.; Pelletier, J.; Whyman, R.; Bickley, J. F.; Steiner, A. Dalton Trans. 2010, 39, 7921.

(37) Kumar, P.; Singh, A. K.; Yadav, M.; Li, P.; Singh, S. K.; Xu, Q.; Pandey, D. S. Inorganica Chim. Acta 2011, 368, 124

(38) Guiry, P. J.; Saunders, C. P. Adv. Synth. Catal. 2004, 346, 497. (39) Loiseleur, O.; Hayashi, M.; Keenan, M.; Schmees, N.; Pfaltz, A. J. Organomet. Chem. 1999, 576, 16.

(40) Chelucci, G.; Orrù, G.; Pinna, G. A. Tetrahedron 2003, 59, 9471.

(41) Braunstein, P. J. Organomet. Chem. 2004, 689, 3953.

(42) Angell, S. E.; Rogers, C. W.; Zhang, Y.; Wolf, M. O.; Jones, W. E. Coord. Chem. Rev. 2006, 250, 1829.

(43) Portnoy, M.; Milstein, D. Organometallics 1994, 13, 600.

(44) Amatore, C.; Carré, E.; Jutand, A.; M’Barki, M. A. Organometallics 1995, 14, 1818.

(45) Krause, J.; Bonrath, W.; Klaus, P. Organometallics 1992, 11, 1158.

(46) Tang, C.-M.; Zeng, Y.; Yang, X.-G.; Lei, Y.-C.; Wang, G.-Y. J. Mol. Catal. A Chem. 2009, 314, 15.

(47) Sieffert, N.; Bühl, M. J. Am. Chem. Soc. 2010, 132, 8056.

(48) Das, P.; Sarmah, P. P.; Borah, M.; Phukan, A. K. Inorganica Chim. Acta 2009, 362, 5001 .

(49) Zhang, Q.; Wu, C.; Zhou, L.; Li, J. Organometallics 2013, 32, 415.

(50) Haibach, M. C.; Guan, C.; Wang, D. Y.; Li, B.; Lease, N.; Steffens,

A. M.; Krogh-Jespersen, K.; Goldman, A. S. J. Am. Chem. Soc. 2013, 135 , 15062 .

(51) Crawford, L.; Cole-Hamilton, D. J.; Drent, E.; Bühl, M. Chem. Eur. J. 2014, 20, 13923.

(52) Becke, A. D. J. Chem. Phys. 1996, 104, 1040.

(53) Perdew, J. P.; Chevary, J. A.; H, V. S.; Jackson, K. A.; Pederson, M. R.; Singh, D. J.; Fiolhais, C. Phys. Rev. B. 1992, 46, 6671.

(54) Perdew, J. P.; Burke, K.; Wang, Y. Phys. Rev. B. 1996, 54, 533.

(55) Arnold, P. L.; Hollis, E.; Nichol, G. S.; Love, J. B.; Griveau, J.-C.;

Caciuffo, R.; Magnani, N.; Maron, L.; Castro, L.; Yahia, A.; Odoh, S. O.; Schreckenbach, G. J. Am. Chem. Soc. 2013, 135, 3841.

(56) Salman, S.; Brédas, J.-L.; Marder, S. R.; Coropceanu, V.; Barlow, S. Organometallics 2013, 32, 6061.

(57) Montero-Campillo, M. M.; Lamsabhi, A. M.; Mó, O.; Yáñez, M.

Theor. Chem. Acc. 2013, 132, 1328.

(58) Ignatov, S. K.; Panteleev, S. V.; Maslennikov, S. V.; Spirina, I. V. Russ. J. Gen. Chem. 2013, 82, 1954.

(59) Wang, L.; Zhang, Y.; He, H.; Zhang, J. Synth. Met. 2013, 167, 51.

(60) Kesharwani, M. K.; Martin, J. M. L. Theor. Chem. Acc. 2014, 133 , 1452 .

(61) Grimme, S.; Antony, J.; Ehrlich, S.; Krieg, H. J. Chem. Phys. 2010, $132,154104$.

(62) Grimme, S.; Ehrlich, S.; Goerigk, L. J. Comput. Chem. 2011, 32, 1456.

(63) Risthaus, T.; Grimme, S. J. Chem. Theory Comput. 2013, 9, 1580.

(64) Becke, A. D.; Johnson, E. R. J. Chem. Phys. 2005, 122, 154104.

(65) Johnson, E. R.; Becke, A. D. J. Chem. Phys. 2006, 124, 174104.

(66) Sieffert, N.; Bühl, M. Inorg. Chem. 2009, 48, 4622.

(67) McMullin, C. L.; Jover, J.; Harvey, J. N.; Fey, N. Dalt. Trans. 2010, $39,10833$.

(68) Peng, C.; Ayala, P. Y.; Schlegel, H. B.; Frisch, M. J. J. Comp. Chem. $1995,17,49$.

(69) Gonzalez, C.; Schlegel, H. B. J. Chem. Phys. 1989, 90, 2154.

(70) Gonzalez, C.; Schlegel, H. B. J. Phys. Chem. 1990, 5523.

(71) Mennucci, B.; Tomasi, J. J. Chem. Phys. 1997, 106, 5151. 
(72) Tomasi, J.; Mennucci, B.; Cancés, E. J. Mol. Struct. Theochem 1999, 464, 211.

(73) Tomasi, J.; Mennucci, B.; Cammi, R. Chem. Rev. 2005, 105, 2999.

(74) Klamt, A.; Mennucci, B.; Tomasi, J.; Barone, V.; Curutchet, C.; Orozco, M.; Luque, F. J. Acc. Chem. Res. 2009, 42, 489.

(75) We computed barriers for the reaction of $21 \rightarrow$ TS21-22 and $25 \rightarrow$ TS26-27 with an alternative methodology of B3PW91-D2/ECP2/PCM // B3PW91-D2/ECP1. The barriers optimised at the level of B3PW91-D3 are lower by 0.3 and $0.4 \mathrm{kcal} / \mathrm{mol}$ respectively. As such, we do not anticipate that optimisation with a dispersion inclusive functional or method would drastically change or alter our conclusions with regards to the overall preferred mechanism. These dispersion-corrected geometries are provided in the ESI.

(76) Frisch, M. J.; Trucks, G. W.; Schlegel, H. B.; Scuseria, G. E.; Robb, M. A.; Cheeseman, J. R.; Scalmani, G.; Barone, V.; Mennucci, B.; Petersson, G. A.; Nakatsuji, H.; Caricato, M.; Li, X.; Hratchian, H. P.; Izmaylov, A. F.; Bloino, J.; Zheng, G.; Sonnenberg, J. L.; Hada, M.; Ehara, M.; Toyota, K.; Fukuda, R.; Hasegawa, J.; Ishida, M.; Nakajima, T.; Honda, Y.; Kitao, O.; Nakai, H.; Vreven, T.; Montgomery, Jr., J. A.; Peralta, J. E.; Ogliaro, F.; Bearpark, M.; Heyd, J. J.; Brothers, E.; Kudin, K. N.; Staroverov, V. N.; Kobayashi, R.; Normand, J.; Raghavachari, K.; Rendell, A.; Burant, J. C.; Iyengar, S. S.; Tomasi, J.; Cossi, M.; Rega, N.; Millam, J. M.; Klene, M.; Knox, J. E.; Cross, J. B.; Bakken, V.; Adamo, C.; Jaramillo, J.; Gomperts, R.; Stratmann, R. E.; Yazyev, O.; Austin, A. J.; Cammi, R.; Pomelli, C.; Ochterski, J. W.; Martin, R. L.; Morokuma, K.; Zakrzewski, V. G.; Voth, G. A.; Salvador, P.; Dannenberg, J. J.; Dapprichs, S.; Daniels, A. D.; Farkas, Ö.; Foresman, J. B.; Ortiz, J. V.; Cioslowski, J.; Fox, D. J. Gaussian 09, Revision A.1, 2009.

(77) Purcell, W.; Conradie, J.; Chiweshe, T. T.; Venter, J. a.; Visser, H. G.; Coetzee, M. P. J. Mol. Struct. 2013, 1038, 220.

(78) Both 1 and $\mathbf{3}$ may bind methanol instead of carbon monoxide and propyne respectively. In both cases, coordination of $\mathrm{MeOH}$ is found to be less favourable than the route illustrated in Scheme 5. Against $\mathrm{CO}$ uptake to form 2 from 1, binding of $\mathrm{MeOH}$ is $2.9 \mathrm{kcal} / \mathrm{mol}(\Delta \mathrm{G}$ B3PW91D3/ECP2/SDD PCM) uphill. Coordination of propyne to form 4 from 3 has a driving force of $15.9 \mathrm{kcal} / \mathrm{mol}$ which is greater than $\mathrm{MeOH}$ coordination with 3 which has a gain of $9.1 \mathrm{kcal} / \mathrm{mol}$. Solvent inhibition of catalytic cycle $\mathbf{A}$ is therefore unlikely and has no noticeable impact on either the selectivity or rate determining steps.

(79) Similar to Mechanism A, complexes with $\mathrm{MeOH}$ coordinated in the vacant site of $\mathbf{8}$ and $\mathbf{8 a}$ have been located. Such intermediates are approximately $9 \mathrm{kcal} / \mathrm{mol}$ and $3 \mathrm{kcal} / \mathrm{mol}$ more stable in free energy (vs 8 / 8a respectively) though do not perturb the overall profile energetics. Associative transition states for propyne undergoing hydride transfer may thus be present but we have not located such in light of the challenging barrier for solvolysis. These solvated intermediates do not alter predicted TOF values for cycle $\mathbf{B}$.

(80) Donald, S. M. A.; Macgregor, S. A.; Settels, V.; Cole-Hamilton, D. J.; Eastham, G. R. Chem. Commun. 2007, 562.

(81) Zuidema, E.; Bo, C.; van Leeuwen, P. W. N. M. J. Am. Chem. Soc. 2007, 129, 3989.

(82) Much debate still surrounds the exact mechanism of such methanolysis processes ${ }^{31-34,76,77,85-88}$ and we note that one commonly proposed route is the loss of a proton from $\mathrm{Pd}(\mathrm{II})$-coordinated methanol into bulk, forming a high-lying methoxide species and allowing for subsequent reductive elimination. Such a mechanism has been studied by Zuidema ${ }^{77}$ and has been found to be considerably uphill. Therefore, more efficient methanolysis routes may well be present but these would do little to resolve the lack of selectivity we find for mechanism $\mathbf{B}$.

(83) Due to the small difference in kinetic energy between TS18-19 and TS18L-19L and the inclusion of moieties which contribute noticeably to dispersive interactions (i.e. phenyl rings), we additionally optimised these complexes at the level of B3PW91-D2/ECP1. At this level, and following minimisation on a dispersion-inclusive potential energy surface, we find that the gross structure of these complexes is retained. However, $\Delta \Delta \mathrm{G}^{\ddagger}$ between these transition states drops from $1.6 \mathrm{kcal} / \mathrm{mol}$ (B3PW91/ECP1) to $0.6 \mathrm{kcal} / \mathrm{mol}$ at the aforementioned level with $\mathbf{T S 1 8 - 1 9}$ being more accessible in both cases. Upon refinement at B3PW91-D2/ECP2/PCM // B3PW91-D2/ECP1 we find that $\Delta \Delta \mathrm{G}^{\ddagger}$ decreases further to less than 0.1 $\mathrm{kcal} / \mathrm{mol}$. A $\Delta \Delta \mathrm{G}^{\ddagger}$ of $0.1 \mathrm{kcal} / \mathrm{mol}$ is also computed at B3PW91D2/ECP2/PCM // B3PW91-D2/ECP1 between TS18-19 6-Me and TS18L-19L 6-Me. This level of theory, therefore, also discounts mechanism C-II from operating.

(84) Johnson, D. G.; Lynam, J. M.; Slattery, J. M.; Welby, C. E. Dalt.

Trans. 2010, 39, 10432 .
(85) Noyori, R.; Yamakawa, M.; Hashiguchi, S. J. Org. Chem. 2001, 66 7931 .

(86) Alonso, D. A.; Brandt, P.; Nordin, S. J. M.; Andersson, P. G. J. Am. Chem. Soc. 1999, 121, 9580.

(87) Reed, A. E.; Weinstock, R. B.; Weinhold, F. J. Chem. Phys. 1985, 83, 735 .

(88) Kozuch, S.; Shaik, S. J. Am. Chem. Soc. 2006, 128, 3355

(89) Kozuch, S.; Lee, S. E.; Shaik, S. Organometallics 2009, 28, 1303.

(90) Kozuch, S.; Shaik, S. Acc. Chem. Res. 2011, 44, 101.

(91) Tijani, J.; Suleiman, R.; El Ali, B. Appl. Organomet. Chem. 2008, 22, 553.

(92) Suleiman, R.; Tijani, J.; El Ali, B. Appl. Organomet. Chem. 2009, 24, 38.

(93) Jimenez-Rodriguez, C.; Eastham, G. R.; Cole-Hamilton, D. J. Dalt. Trans. 2005, 2, 1826 . 
TOC Graphic

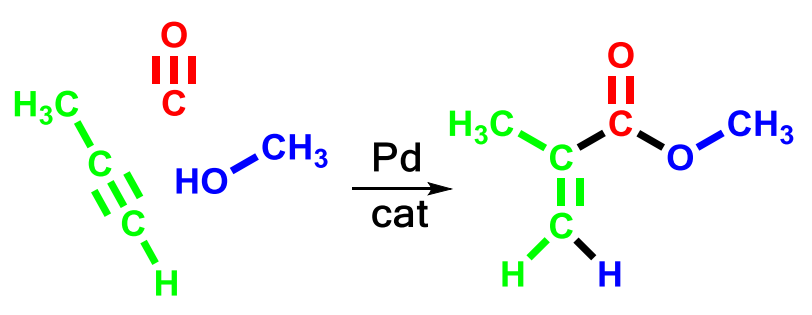

